\title{
Hippo/MST1 signaling mediates microglial activation following acute cerebral ischemia-reperfusion injury
}

Siqi Zhao ${ }^{1}$, Jie Yin ${ }^{1,2}$, Lujun Zhou ${ }^{1,2}$, Feng Yan ${ }^{3}$, Qing He ${ }^{1,2}$, Li Huang ${ }^{1}$, Shengyi Peng ${ }^{1}$, Junying Jia ${ }^{5}$, Jinbo Cheng $^{1}$, Hong Chen ${ }^{1}$, Wufan Tao ${ }^{4}$, Xunming $\mathrm{Ji}^{3}$, Yun $\mathrm{Xu}^{6}$, Zengqiang Yuan ${ }^{1,7}$

1. Institute of Biophysics, Chinese Academy of Sciences, Beijing 100101, China

2. College of Life Sciences, Graduate School of the Chinese Academy of Sciences, Beijing 100049, China

3. The Cerebrovascular Diseases Research Institute, Xuanwu Hospital of Capital Medical University, Beijing 100053, China

4. School of Life Sciences, Fudan University, Shanghai 200433, China

5. Core Facility Center, Institute of Biophysics, Chinese Academy of Sciences, Beijing 100101, China

6. Department of Neurology and Radiology, Affiliated Drum Tower Hospital, Nanjing University Medical School, Nanjing, Jiangsu, 210008, PR China

7. Correspondence:

Zengqiang Yuan, PhD. State Key Laboratory of Brain and Cognitive Sciences, Institute of Biophysics, Chinese Academy of Sciences, Beijing 100101, China. Email: zqyuan@ibp.ac.cn 


\begin{abstract}
Cerebral ischemia-reperfusion injury is a major public health concern that causes high rates of disability and mortality in adults. Microglial activation plays a crucial role in ischemic stroke-induced alteration of the immune microenvironment. However, the mechanism underlying the triggering of microglial activation by ischemic stroke remains to be elucidated. Previously, we demonstrated that the protein kinase Hippo/MST1 plays an important role in oxidative stress-induced cell death in mammalian primary neurons and that the protein kinase c-Abl phosphorylates MST1 at Y433, which increases MST1 kinase activity. Microglial activation has been implicated as a secondary detrimental cellular response that contributes to neuronal cell death in ischemic stroke. Here, we are the first, to our knowledge, to demonstrate that MST1 mediates stroke-induced microglial activation by directly phosphorylating $\mathrm{IKBa}$ at residues S32 and S36. We further demonstrate that Src kinase functions upstream of MST1-IKB signaling during microglial activation. Specific deletion of MST1 in microglia mitigates stroke-induced brain injury. Therefore, we propose that Src-MST1-IkB signaling plays a critical role in stroke-induced microglial activation. Together with our previous work demonstrating that MST1 is important for oxidative stress-induced neuronal cell death, our results indicate that MST1 could represent a potent therapeutic target for ischemic stroke.
\end{abstract}

Key words: ischemia; microglia; Hippo/MST1; Src; IkB 


\section{Introduction}

Oxidative stress impacts various biological processes, including cell survival, aging and inflammation as well as the pathogenesis of many neurological disorders of the brain (Chong et al., 2005). Oxidative stress is thought to trigger gene expression in either programmed cell death or innate immunity (Finkel, 2000; Wu et al., 2015). However, the intracellular mechanisms stimulated by oxidative-stress remain incompletely understood. Ischemic stroke is a major public health concern that causes high rates of disability and mortality in adults. Although neuronal cell death has been placed at the center stage of research on ischemia-induced injury, a growing body of evidences indicates that microglial activation in the infarcted area is also functionally significant and plays important roles in oxidative-stress induced neuronal cell death (Davalos et al., 2005). When stroke occurs, oxidative stress induces neuronal damage, which releases danger-associated molecular pattern molecules (DAMPs) and purines (ATP) that activate receptors in microglia, including Toll-like receptors (TLRs) and scavenger receptors, resulting in the accumulation of active microglia around the injured regions. The recruited microglial cells subsequently scavenge the dead cells and debris (Schilling et al., 2005). However, the overwhelming microglial activation could be detrimental for the neurons, suggesting that besides the reduction of neuronal cell death, the inhibition of microglial activation might be a potential therapeutic strategy in the treatment of the stroke.

It has been reported that the Hippo signaling pathway plays important roles in regulating organ size and cell migration, differentiation, proliferation, and apoptosis in Drosophila and mammals. The mammalian Ste20-like kinase1/2 (MST1/2), which shares the greatest homology with Drosophila Hippo, functions as a core kinase in Hippo/MST signaling (Csibi and Blenis, 2012; Del Re et al., 2014; Lange et al., 2015; Mi et al., 2014). Protein kinases play a central role in regulating cellular responses to oxidative stress (Finkel, 2000). Consistent with this, our previous reports demonstrated that MST1 is critical for oxidative stress-induced neuronal cell death (Lehtinen et al., 2006; Xiao et al., 2011).

Interestingly, MST1 is functional in the peripheral immune response. Du et al and Zhou et al reported that MST1 plays important roles in T cell proliferation, migration, and development (Du et al., 2014; Zhou et al., 2008). In addition, recent study suggested that DN-MST1 (the domain negative form of 
MST1) inhibited nuclear factor-kappa B (NF-kB) activation in cardiac fibroblasts (Odashima et al., 2007), thus linking Hippo/MST signaling with the classical immune pathway. Cerebral ischemia causes NF-KB activation followed by transcriptional regulation of pro-inflammatory mediators (Venna et al., 2012) (Zhang et al., 2005). In particular, NF-kB activation in microglia contributes to delayed inflammation and neurotoxicity (Kaushal and Schlichter, 2008).

We previously demonstrated that MST1 is important for oxidative-stress-induced neuronal cell death (Lehtinen et al., 2006; Xiao et al., 2011). As a ubiquitously expressed protein, whether MST1 is also involved in microglial activation remains unknown.

In this study, we used Lyz2Cre:Mst1f/f mice, in which MST1 was deleted in the myeloid compartment, such as microglia in the central nervous system (CNS) and monocytes in the periphery, to induce transient middle cerebral artery occlusion (tMCAO) in these mice and found that MST1 precipitates stroke-induced microglial activation and phosphorylates IkB, leading to NF-kB activation. Moreover, we constructed a siRNA library targeting 32 putative non-receptor tyrosine kinases and screened identified Src kinase as an upstream regulator of MST1-IKB signaling during stroke-induced microglial activation. Taken together, we demonstrated that Src/MST1/lkB signaling plays a critical role in the microglial activation induced by cerebral ischemia, which implies that this signaling pathway may be a potential therapeutic target for stroke related diseases. 


\section{Materials and Methods}

\subsection{Reagents}

The following reagents were purchased: AZD0530 (Selleckchem, Houston, TX, USA) and lipopolysaccharide (LPS; Sigma, St. Louis, MO, USA).

\subsection{Cell culture}

To assess whether MST1 is involved in microglial activation in vitro, the microglial cell lines N9 or BV2 were used. The murine microglial cell line N9 was kindly provided by Prof. J.M. Wang (Laboratory of Molecular Immunoregulation, Center for Cancer Research, NCI, National Institutes of Health, USA). Cells were cultured in Iscove's Modified Dulbecco's Medium (IMDM; Gibco, Waltham, MA, USA) supplemented with $5 \%$ fetal bovine serum (FBS), $2 \mathrm{mM}$ glutamine, $100 \mathrm{U} / \mathrm{ml}$ penicillin, and $100 \mu \mathrm{g} / \mathrm{ml}$ streptomycin at $37^{\circ} \mathrm{C}$ in a humidified atmosphere containing $5 \% \mathrm{CO}_{2}$. Mouse primary microglia were isolated from C57BL/6 mice on postnatal day 1. Briefly, the meninges and blood vessels of the mouse cortex were removed. Cortical tissue was dissociated with $0.25 \%$ trypsin at $37^{\circ} \mathrm{C}$ for 7 min, and the cell suspension was then filtered through a $40-\mu \mathrm{m}$ diameter nylon mesh. The cells were collected by centrifugation at $1000 \mathrm{rpm}$ for $5 \mathrm{~min}$, re-suspended in Dulbecco's modified Eagle's medium/F-12 nutrient mixture (DMEM-F12, Gibco, Waltham, MA, USA), and then plated in culture flasks. Cells were incubated at $37^{\circ} \mathrm{C}$ in a humidified atmosphere (containing $5 \% \mathrm{CO}_{2}$ ). After 9 to11 days, the flasks were shaken on a rotary shaker at $200 \mathrm{rpm}$ for $1 \mathrm{~h}$. The resulting cell suspension, which was enriched in microglia, was plated into culture dishes, to which the cells adhered after $30 \mathrm{~min}$ at $37^{\circ} \mathrm{C}$. The purity of the cells obtained was $>95 \%$ as verified by immunocytochemistry using monoclonal antibodies against Iba-1 (Wako, Chuo-ku, Japan) and CD11b/c (Abcam, Cambridge, MA, USA) (data not shown) (Xiao et al., 2011). After the microglia were separated, the dishes were shaken for $14 \mathrm{~h}$ to 
remove the remaining adhered microglia and oligodendrocytes. Next 15 to 20-day-old astrocytes were used in the experiments (Ducis et al., 1990). Primary neurons were isolated from the cerebral cortex of embryonic day 16 (E16) C57BL/6 mice (Pan et al., 2008). After dissection and removal of the meninges, the cortices were minced and dissociated with $0.25 \%$ trypsin at $37^{\circ} \mathrm{C}$ for $7 \mathrm{~min}$. The reaction was stopped by addition of $10 \%$ FBS and the tissue was mechanically dissociated with a Pasteur pipette. Cells were seeded into 6 -well plates $\left(1 \times 10^{5}\right.$ cells/well $)$ with $0.01 \%$ poly-l-lysine pre-coating, and cultured in Neurobasal Medium supplemented with 2\% B27, $100 \mathrm{U} / \mathrm{ml}$ penicillin and $100 \mu \mathrm{g} / \mathrm{ml}$ streptomycin. The murine microglial cell line BV2 and the 293T cell line were purchased from the Cell Resource Center, Institute of Basic Medical Science, Peking Union Medical University (Beijing, China).

\subsection{MTT reduction assay}

Cell viability was evaluated using the MTT reduction assay (Chang et al., 1998). Briefly, (3-[4,5-Dimethylthiazol-2-yl]-2,5-diphenyltetrazolium bromide (MTT) was obtained from Sino-American Biotechnology (Beijing, China). After various treatments, the medium was removed and the cells were incubated with MTT $(0.25 \mathrm{mg} / \mathrm{ml})$ for $3 \mathrm{~h}$ at $37^{\circ} \mathrm{C}$. The formazan crystals in the cells were solubilized with DMSO. MTT formazan levels were determined by measuring its absorbance at $490 \mathrm{~nm}$ with a SPECTRA (shell) Reader (TECAN, Grödig, Austria).

\subsection{Mouse model of focal cerebral ischemia-reperfusion injury}

To identify the function of MST1 in brain ischemia, we used MST1 knockout mice or mice with a conditional knockout in microglia/macrophage. $\mathrm{Mst1}^{-1-}$ mice were kindly supplied by Prof. Wufan Tao (Fudan University, Shanghai, China). For the MCAO experiments, 8- to 10-week old Mst $1^{-/-}$or $M s t 1^{+/+}$ mice in a $129 / \mathrm{Sv}$ genetic background were anesthetized with $2 \%$ enflurane $(\mathrm{v} / \mathrm{v})$ in $68 \%$ nitrous oxide 
and $30 \%$ oxygen and maintained under $1.5 \%$ enflurane during surgery. The body temperature was maintained at $37 \pm 0.5^{\circ} \mathrm{C}$ using a feedback-regulated heating pad (Harvard). Cerebral blood flow was measured via laser Doppler flowmetry (Perimed, Datavägen 9 A, Sweden). The right external carotid artery was transected, and a silicone-coated 6-0 monofilament was advanced until its tip occluded the origin of the middle cerebral artery (MCA). For transient MCAO (tMCAO), reperfusion was performed $1 \mathrm{~h}$ after occlusion by removing the suture occluding the MCA. Cerebral blood flow dropped to $<20 \%$ of the baseline level after placement of the filament $(0.22 \mathrm{~mm}$ tip) and recovered to $>70 \%$ of baseline after the removal of the filament (at $1 \mathrm{~h}$ after ischemia). Twenty-four hours after tMCAO surgery, neurological outcomes were assessed, and then the mice were euthanized to measure infarct size, stain for lba-1 (1:500, Wako, Chuo-ku, Japan) and measure mRNA levels of tumor necrosis factor alpha (TNF- $\alpha$ ) and interleukin 6 (IL-6). To generate microglia-specific Mst1-/mice, mice harboring exon 4 of the Mst1 gene flanked by loxP sites (129/Sv; supplied by Prof. Wufan Tao, Fudan University, Shanghai, China) were crossed with mice expressing Cre under the control of the mouse Lyz2 promoter (B6; Lyz2-Cre, purchased from Model Animal Research Center, Nanjing University, China). Lyz2Cre:Mst $1^{\mathrm{f} /+}$ mice were intercrossed to generate Lyz2Cre:Mst1//f mice for the MCAO experiments. Twenty-four hours after tMCAO surgery, the mice were euthanized for measurement of infarct size, neurological outcome, staining for lba-1 (1:500, Wako, Chuo-ku, Japan), NeuN (1:50, Millipore, Darmstadt, Germany) and terminal deoxynucleotidyl transferase dUTP nick-end labeling (TUNEL staining kit, Millipore, Darmstadt, Germany) For determining levels of phosphorylation of IKB- $\alpha$ (1:1000, CST, Danvers, MA, USA) and total IKB- $\alpha,(1: 1000$, CST, Danvers, MA, USA), the mice were euthanized $6 \mathrm{~h}$ after reperfusion. For in vivo experiments using AZD0530 (i.p., $10 \mathrm{mg} / \mathrm{kg}$ ), wild-type C57BL/6 mice were used. We treated tMCAO-exposed mice with AZD0530 
(10 mg/kg, i.p.) at $0,2,4$, or $6 \mathrm{~h}$ after reperfusion and measured the infarct size, neurological outcome and staining of Iba-1 at $24 \mathrm{~h}$ after reperfusion. For determining levels of phosphorylation of MST1 at Y433 (1:200, CKIPQDGDpYEFLKSW), Src, total Src, MST1 and IKB- $\alpha$ (1:1000, all from CST, Danvers, MA, USA), the mice were euthanized $6 \mathrm{~h}$ after reperfusion. All animal experiments were approved by the Institutional Animal Care and Use Committee of the Institute of Biophysics at the Chinese Academy of Sciences.

\subsection{Infarct volume and neurological evaluation}

Mice were anesthetized $24 \mathrm{~h}$ after $\mathrm{MCAO}$, and the brains were frozen at $-80^{\circ} \mathrm{C}$ for $2 \mathrm{~min}$, cut into five 1-mm serial coronal sections, and incubated in a 1.5\% 2,3,5-triphenyltetrazolium chloride (TTC; v/v, Sigma, St. Louis, MO, USA) solution for 5 min at $37^{\circ} \mathrm{C}$ according to previous reports (Di et al., 1997; Goldlust et al., 1996; Umemura et al., 2007; Venna et al., 2012; Wu et al., 2012). Furthermore, we found that there is no significant difference of TTC staining between frozen brains and non-frozen brain as shown in Figure $1 \mathrm{~A}$ and Figure $\mathrm{S} 1$. Then, the stained slices were transferred to a $4 \%$ paraformaldehyde solution. Images of five brain sections were recorded, and analysis of the infarct volume was performed using ImageJ software (a public domain, Java-based image processing program developed at $\mathrm{NIH}$, National Institutes of Health, USA). The infarct volume was determined by measuring the TTC-staining negative area vs the total area in the serial coronal sections. An observer who was blind to the mouse genotype performed the neurological evaluation according to a modified scoring system (Hara et al., 1996). Briefly, the criteria were as follows: grade $0=$ no observable neurological deficits; grade 1 = failed to extend right forepaw; grade 2 = circled to the right; grade $3=$ fell to the right; grade $4=$ could not walk spontaneously and grade $5=$ dead. Neurological deficits were evaluated $24 \mathrm{~h}$ after MCA occlusion. 


\section{Plasmids and transfection}

The use of the Flag-MST1 (WT, Y433F), GST-MST1 (WT, KD), and GFP-MST1 plasmids has been previously described (Lehtinen et al., 2006; Xiao et al., 2011). The Flag-IKBa WT and S32/36A plasmids were kindly provided by Prof. Yusheng Cong (Hangzhou Normal University, Hangzhou, China). Myc-c-Src was cloned into pCMV-Myc at its EcoRI and Kpnl sites via PCR. Fragments of the GST-I IKBa plasmid were inserted into pGEX4T1 at its BamHI and EcoRI restriction sites via polymerase chain reaction (PCR). Src (K297M) and other mutants were generated via site-directed mutagenesis. All mutations were verified by sequencing. Mammalian RNAi constructs were designed as previously described (Gaudilliere et al., 2002). The shRNA targeting sequences used included the following: MST1 shRNA: GCCCTCACGTAGTCAAGTATT; $\quad$ Src shRNA: GCAAGATCACTAGACGGGAAT. The p65 siRNA and negative control were chemically synthesized and purified using a commercial source (GenePharma, Shanghai, China). The siRNA library targeting 32 putative non-receptor tyrosine kinases was purchased from Dharmacon (Thermo Fisher Scientific, Waltham, MA, USA). Unless stated otherwise, all transfections were performed in complete medium using Lipofectamine 2000 reagent (Invitrogen, Waltham, MA, USA) following to the manufacturer's protocol.

\subsection{Immunofluorescence}

Freshly fixed primary microglial cells were first washed with phosphate-buffered saline (PBS) thrice and blocked with $20 \%$ goat serum in PBS containing $0.2 \%$ Triton $\mathrm{X}-100$ to reduce nonspecific antibody binding. Microglial cells were then incubated with the primary antibody, p-MST1-Y433 (1:50, CKIPQDGDpYEFLKSW) and CD11b (1:200, Abcam), at $4^{\circ} \mathrm{C}$ overnight. After washing with PBS three times, Alexa Fluor 488- or 546-conjugated secondary antibodies (Invitrogen) were used to detect the 
signal. The secondary antibody was incubated at room temperature for $1 \mathrm{~h}$, and nuclear morphology was visualized using the DNA dye Hoechst 33258 (Sigma).

Mice were anesthetized via i.p. injection of avertin $(250 \mathrm{mg} / \mathrm{kg})$ and perfused, and their brains were postfixed. Coronal brain sections of $20 \mu \mathrm{M}$ thickness were sliced using a cryostat. To identify neuronal apoptosis, we performed TUNEL staining (Millipore, Darmstadt, Germany) and immunocytochemistry using a monoclonal antibody against NeuN (1:50, Millipore, Darmstadt, Germany). For microglial staining, we used the rabbit anti-lba-1 (1:500, Wako, Chuo-ku, Japan) and mouse anti-CD11b (1:200, Abcam, Cambridge, MA, USA) antibodies.

\subsection{Immunoblotting, coimmunoprecipitation, and kinase assay}

Immunoblotting and coimmunoprecipitation were performed as previously described (Yuan et al., 2010). Antibodies against the following proteins were used: GST (1:1000), GAPDH (1:5000), IKB $\alpha$ (1:1000), $\beta$-tubulin (1:5000), and $\beta$-actin (1:5000) (all from Santa Cruz Biotechnology, Santa Cruz, CA, USA); FLAG-M2 (1:5000), phosphotyrosine (p-Tyr) (4G10) and NeuN (1:50) (all from Millipore, Darmstadt, Germany); GFP (1:5000, Invitrogen, Waltham, MA, USA); and phospho-Src (Y416) (1:1000), phospho-IKBa (S32/36) (1:1000), and Src (1:1000)(all from CST, Danvers, MA, USA). A polyclonal antibody against Y433-phosphorylated MST1 was generated in rabbits (NewEast Biosciences, King of Prussia, PA, USA) using a synthetic peptide corresponding to phospho-MST1 (425-439) [p-Y433] (1:200) [CKIPQDGDpYEFLKSW], and its specificity has been characterized in our previous reports (Xiao et al., 2011). In vitro kinase assays were performed as previously described (Xiao et al., 2011). Briefly, immunoprecipitated wild-type and kinase-dead Src were incubated in $1 \mu \mathrm{g}$ of GST-MST1 or GST-MST1-Y433F in reaction buffer containing $30 \mathrm{mM}$ Tris $(\mathrm{pH}$ 7.4), $20 \mathrm{mM} \mathrm{MgCl} 2,1 \mathrm{mg} / \mathrm{ml} \mathrm{BSA}$, and $100 \mu \mathrm{M}$ ATP. Wild-type and mutant (S32/36A) GST-tagged 


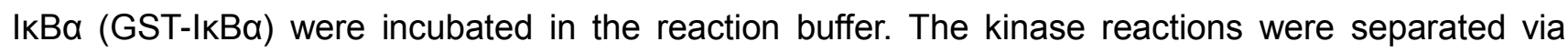
sodium dodecyl sulfate polyacrylamide gel electrophoresis (SDS-PAGE) and analyzed via either autoradiography or immunoblotting using the indicated antibody.

\subsection{Lentivirus construction and infection}

A pLKO.1 vector containing a shRNA sequence was co-transfected with VSV-G and pCMV-dR8.12 plasmids into 293T cells. Viruses were collected from the supernatant at 24 and $48 \mathrm{~h}$ after transfection. Ultracentrifugation was performed to enrich the virus concentration. Stably silenced BV2 cell clones were established by infecting the cells with the corresponding lentivirus. A virus produced from the empty pLKO.1 vector was used to generate control cells. The cells were selected in complete medium containing $5 \mu \mathrm{g} / \mathrm{mL}$ puromycin $24 \mathrm{~h}$ after infection. For the construction of the lentiviral vectors expressing Src-WT, Src-KD, Mst1-WT, Mst1-Y433F, Mst1-KD, IKBa-WT or IKBa-S32/36A, each fragment was cloned into a pCDH-EF1-MCS-T2A-Puro or pCDH-EF1-MCS-T2A-copGFP lentiviral expression vector (System Bioscience, Mountain View, CA, USA) according to a previously described method (Kim et al., 2012). The lentiviral expression vectors described above were transfected into 293FT cells using VSV-G and LnV plasmids. Viruses were collected from the supernatant at 24 and $48 \mathrm{~h}$ after transfection. Stably overexpressing BV2 cell clones were established by infecting the cells with the corresponding lentivirus. The cells were selected in complete medium containing $5 \mu \mathrm{g} / \mathrm{mL}$ puromycin $24 \mathrm{~h}$ after infection. $\mathrm{GFP}^{+}$cells were isolated and sorted via flow cytometry (BD Influx, San Jose, CA, USA).

\subsection{RNA extraction, reverse transcription and quantitative real-time PCR (qRT-PCR)}

Total RNA was isolated from cells using TRIzol reagent (Invitrogen, Waltham, MA, USA), and reverse transcription was performed using the One-Step first strand cDNA synthesis kit (Transgen, Beijing, 
China). Quantitative real-time polymerase chain reaction (qRT-PCR) was performed using 2x SYBR Green PCR master mix (Transgen, Beijing, China) in an Agilent Mx3005P qRT-PCR system. The melting temperature profiles of the final products were used to ensure amplicon specificity. The relative fold-change in the expression of each mRNA was calculated using the $\Delta \Delta \mathrm{Ct}$ method relative to the expression of GAPDH. The qRT-PCR primers used are listed as follows:

mGAPDH-realtime-F: 5-AGGTCGGTGTGAACGGATTTG-3, mGAPDH-realtime-R: 5-GGGGTCGTTGATGGCAACA-3;

mTNF-a-realtime-F: 5-CAGGCGGTGCCTATGTCTC-3,

mTNF-a-realtime-R: 5-CGATCACCCCGAAGTTCAGTAG-3; and

mIL-6-realtime-F: 5-TCTATACCACTTCACAAGTCGGA-3, mIL-6-realtime-R: 5-GAATTGCCATTGCACAACTCTTT-3.

\subsection{Enzyme-linked immunosorbent assay (ELISA)}

Primary microglia or BV2 cells were seeded on 96 -well plates $\left(1 \times 10^{5}\right.$ cells/well). Cell culture supernatants were collected and subjected to ELISA for TNF- $\alpha$ and IL-6 using ELISA kits (Biolegend, San Diego, CA, USA) following to the manufacturer's instructions.

\subsection{Oxygen glucose deprivation in cultured cells}

To simulate the brain ischemia-induced microglial activation in vitro, we adopt the oxygen glucose deprivation (OGD) model to stimulate microglia and assess the role of MST1 in microglial activation. For OGD, the cells were rinsed twice and incubated in glucose-free Minimum Essential Medium (MEM; Gibco, Waltham, MA, USA). Then, the cultured cells were transferred to an anaerobic chamber containing a mixture of $94 \% \mathrm{~N}_{2}, 1 \% \mathrm{O}_{2}$, and $5 \% \mathrm{CO}_{2}$ at $37^{\circ} \mathrm{C}$ for $2 \mathrm{~h}$, followed by reoxygenation for $24 \mathrm{~h}$. 


\subsection{Measurement of NF-KB activation}

Primary microglial cells from wild type or MST1 knockout mice were cultured in 24-well plates and transfected with $0.5 \mu \mathrm{g} /$ well pNFkB-luc reporter construct and $10 \mathrm{ng} /$ well $\mathrm{pRL}-\mathrm{TK}$ construct. The cells were then cultured in the presence or absence of LPS $(1 \mu \mathrm{g} / \mathrm{ml})$ for $12 \mathrm{~h}$. Both firefly luciferase and Renilla luciferase activities were measured.

\subsection{Statistical analysis}

Statistical analysis of the data was performed via one-way analysis of variance (ANOVA) followed by a Bonferroni multiple comparisons test or Student's $t$-test using GraphPad Prism 5 software. The data are presented as the mean \pm standard error of the mean (SEM). Neurological deficit scores were evaluated for statistical significance by the Mann-Whitney $U$ analysis. ${ }^{*} \mathrm{P}<0.05$, ${ }^{* *} \mathrm{P}<0.01$, ${ }^{* * *} \mathrm{P}<$ 0.001 or no significant difference (NS) denote the significance thresholds. 


\section{Results}

\subsection{The function of MST1 in microglial activation}

To determine whether MST1 is involved in ischemia-induced microglial activation, wild-type or Mst1/mice were subjected to right-sided tMCAO, which involved $1 \mathrm{~h}$ of MCAO followed by $24 \mathrm{~h}$ of reperfusion. The extent of brain injury was assessed via standard staining with triphenyltetrazolium chloride (TTC), a colorimetric redox indicator that distinguishes metabolically active from inactive tissue (Figure $1 \mathrm{~A}$ and $1 \mathrm{~B}$ ). The results revealed significantly smaller infarct volumes and greater neurological function after tMCAO in $\mathrm{Mst1/-}^{-/}$mice compared with wild-type mice (Figure 1C and 1D). Consistently, we found an increased number of microglia, stained by CD11b positive cells, in the ischemic striatum of the tMCAO group compared with the sham group. This result indicates that microglial activation after stroke (Figure 1E and 1F). Interestingly, fewer microglia surrounding the infarct were observed in the brains of the $\mathrm{Mst1}^{-/-}$mice compared with wild-type mice. Furthermore, the production of TNF- $\alpha$ and IL-6 was decreased in Mst1-- mice (Figure 1G), indicating that MST1 is involved in ischemia-induced microglial activation and inflammation. Moreover, the microglial cells from $\mathrm{Mst}^{1-1}$ mice did not affect the cell viability when compared with wild type microglia (Figure $1 \mathrm{H}$ ). OGD and lipopolysaccharide (LPS) application induce microglial activation in vitro (Burguillos et al., 2015; Kaushal and Schlichter, 2008). Thus, we next explored whether MST1 is involved in OGD- or LPS-induced microglial activation, and we found that MST1 knockdown reduced the expression of TNF- $\alpha$ (Supplementary Information, Figure S2A-D). Accordingly, in primary microglial cultures, MST1 deletion significantly inhibited the OGD or LPS-induced production of TNF- $\alpha$ and IL-6 (Figure 1 I and 1J). Interestingly, re-introduction of MST1 into $\mathrm{Mst1}^{-1-}$ microglia rescued IL-6 levels (Supplementary Information, S2F). The rescue effect on TNF- $\alpha$ induction is only partial, which might be due to the transfection efficiency of exogenous MST1 (only approximately $30 \%$ of the cells were transfected) (Supplementary Information, Figure S2E). Taken together, these findings strongly support the hypothesis that MST1 is involved in pathological microglial activation.

\subsection{Phosphorylation of MST1 at tyrosine 433 is important for microglial activation}


We previously reported that the protein kinase c-Abl phosphorylates MST1 at tyrosine 433 (Y433), which triggers the stabilization and activation of MST1 during oxidative stress-induced neuronal cell death (Xiao et al., 2011). Because both neuronal cell death and microglial activation are detrimental to ischemia-mediated brain injury, we investigated whether the phosphorylation of MST1 Y433 occurs during microglial activation in addition to neuronal cell death. We found that the levels of MST1 phosphorylation at Y433 were increased following LPS-, OGD-, or tMCAO-induced microglial activation (Figure 2A-C). The antibody against MST1-p-Y433 specifically labels theY433 phosphorylation of MST1 in ischemic brain tissues as shown in Figure S3. We found that the Y433 phosphorylation of MST1 was absent in the MST1 knockout mice. Immunofluorescence also showed increased phosphorylation of MST1 at Y433 under these conditions (Figure 2D and 2E). To evaluate the function of MST1 phosphorylation at Y433 in activated microglia, we expressed MST1 Y433F, in which Y433 was replaced with phenylalanine to mimic the non-phosphorylated form of MST1, in primary microglia. We observed that the Y433F mutation attenuated LPS-stimulated TNF- $\alpha$ and IL-6 mRNA expression (Figure $2 \mathrm{~F}$ and $2 \mathrm{G}$ ). Therefore, we concluded that the tyrosine phosphorylation of MST1 at Y433 plays an important role in microglial activation.

\subsection{Src acts as an upstream activator of MST1 during microglial activation}

To further determine whether upstream tyrosine kinases direct the phosphorylation of MST1 at Y433 during microglial activation, we constructed a siRNA library targeting 32 putative non-receptor tyrosine kinases. We observed that knockdown of Src or Tnk2 reduced the phosphorylation of MST1 at Y433 (Figure 3A). Next, we found that Src, but not Tnk2, phosphorylates MST1 at Y433 both in vitro and in cultured cells (Figure $3 \mathrm{~B}$ and $3 \mathrm{C}$, and data not shown). To further confirm whether SrC regulates the activation of MST1, we constructed a stably Src-silenced BV2 cell line, and we found that Src knockdown significantly reduced Y433 phosphorylation of MST1 (Figure 3D). Furthermore, we observed that AZD0530, a specific Src kinase inhibitor in phase II/III trials as chemotherapy for ovarian cancer, inhibited the phosphorylation of MST1 at Y433 induced by OGD or LPS treatment (Figure 3E and 3F). We tested the viability of BV2 cells exposed to AZD0530, as shown in Figure 3G and found that AZD0530 did not affect viability. Consistent with previous reports (Socodato et al., 
2015), AZD0530 treatment markedly inhibited TNF-a production induced by LPS or OGD in microglia (Figure $3 \mathrm{H}$ and $3 \mathrm{I})$.

Ectopic expression of Src kinase increased the levels of inducible nitric oxide synthase (iNOS), and this effect was inhibited by co-expression of MST1 Y433F in BV2 cells. Moreover, the expression of K297M (kinase-dead) Src kinase reduced wild-type MST1 expression-triggered iNOS expression in BV2 cells. These data suggest that Src kinase functions as an upstream activator of MST1 by phosphorylating MST1 at Y433 during microglial activation (Figure 3J).

\subsection{MST1 regulates inflammatory factors release through NF-KB pathway}

To investigate the potential role of MST1 in the activation of NF-KB signaling, we examined the phosphorylation levels of IKB induced by LPS in primary cultures of microglia from wild-type or Mst1/mice. A significant decrease in IKB phosphorylation was noted in MST1-deficient microglia (Figure 4A and 4B). Because MST1 is a protein kinase, we next explored whether MST1 directly phosphorylates the IKB protein. To further validate the phosphorylation of $\mathrm{IKB}$ at $\mathrm{S} 32$ and $\mathrm{S} 36$ in vitro, we coexpressed MST1-WT with IKBS32/36A and found that MST1-WT failed to induce IKB phosphorylation at S32 and S36 (Figure 4C). Moreover, we overexpressed MST1-WT, IKB-WT and IKBS32/36A in 293T cells and found that MST1 phosphorylated IKB-WT at sites S32 and S36 but not phosphorylate the IKBS32/36A form (Figure 4D). These results support the conclusion that MST1 phosphorylates IKB at S32 and S36 both in vitro and in cultured cells. Interestingly, the mutant form of IKB (S32/36A) inhibits the iNOS expression induced by MST1 overexpression in LPS-treated BV2 cells, whereas MST1 K59R (kinase-dead) blocks wild-type IKB expression-induced iNOS upregulation (Figure 4E and 4F). In addition, p65 RNAi significantly blocks TNF-a release induced by MST1 overexpression in LPS-treated BV2 cells (Figure 4G). We also observed that LPS-induced NF-KB activation was markedly reduced in $\mathrm{Mst1}^{-1-}$ microglial cells compared with wild type microglial cells (Figure $4 \mathrm{H}$ ). Taken together, these findings indicate that MST1 regulates the pro-inflammatory factors production through NF-kB pathway.

3.5. Loss of MST1 in microglia/macrophages protects against cerebral ischemia-induced brain injury 
Given that MST1 deletion inhibits microglial activation induced by OGD or LPS, we hypothesized that the microglia-specific deletion of MST1 might exert a neuroprotective effect in ischemic stroke by preventing microglial activation. To test this hypothesis, we generated Lyz2Cre:Mst1/f mice, in which MST1 was deleted in microglia/macrophages. Then, Mst1 ${ }^{f / f}$ and Lyz2Cre: Mst $1^{t / f}$ mice were subjected to right-sided tMCAO, which involved $1 \mathrm{~h}$ of MCAO followed by $24 \mathrm{~h}$ of reperfusion. Significantly decreased infarct volume and enhanced neurological function after tMCAO were observed in Lyz2Cre:Mst ${ }^{f / f}$ mice (Figure 5A-C). To confirm the specificity of MST1 deletion, we isolated microglia, astrocytes, and neurons from the cortex of $M s t 1^{t / f}$ mice and Lyz2Cre:Mst1/f mice. MST1 was deleted only in microglia, not astrocytes or neurons (Figure 5D). We consistently observed a marked reduction in Iba-1-positive hypertrophied microglia in the brain slices from the Lyz2Cre:Mst1 $1^{\text {f/f }}$ mice after tMCAO (Figure 5E and 5F). To further investigate the protective effect of MST1 deficiency-mediated microglial inhibition, we performed TUNEL staining to examine cell death surrounding the infarct $24 \mathrm{~h}$ after tMCAO. As expected, MST1 deletion in microglia reduced the extent of ischemia-induced neuronal death (Figure 5G-I).

IKB phosphorylation and degradation is an indicator of NF-KB activation during ischemic stroke (Herrmann et al., 2005), and we observed suppression of $\mathrm{I} \mathrm{KBa}$ protein phosphorylation and degradation in brain tissue from microglia-specific MST1-deficient mice following stroke (Figure 5J and $5 \mathrm{~K})$. Taken together, these results indicate that a deficiency in MST1 in microglia might improve outcomes after ischemic stroke.

\subsection{Src inhibition improves outcome after ischemic stroke}

Because Src acts upstream of MST1 to modulate microglial activation, we examined whether Src inhibition protects against ischemic injury. We treated mice subjected to stroke with AZD0530, a specific Src inhibitor (10 mg/kg, i.p.), at 0, 2, 4, or $6 \mathrm{~h}$ after reperfusion and examined the infarct size and neurological outcome at $24 \mathrm{~h}$ after reperfusion. Interestingly, AZD0530 significantly reduced the infarct size and neurological deficits (Figure 6A-C). Immunostaining revealed that Src inhibition significantly reduced the number of hypertrophied microglia in the striatum of the mice subjected to tMCAO (Figure 6D and 6E). Furthermore, AZD0530 inhibited MST1 phosphorylation at Y433 and IKB 
degeneration in striatal tissue following tMCAO (Figure 6F and 6G). Taken together, these data suggest that Src kinase functions as an upstream activator of MST1 and NF-kB signaling to induce microglial activation; thus, Src inhibition is implicated as a therapeutic strategy for ischemic brain injury. 


\section{Discussion}

Brain ischemic stroke-mediated oxidative stress not only impaired neuronal cell death but also promotes the activation of microglia. Dying neurons release neurotoxic factors that promote the activation of microglia, which then further produce inflammatory factors, triggering neuronal cell death in the CNS. This process occurs in diseases such as stroke, Alzheimer's disease (AD), and Parkinson's disease (PD) (ladecola and Anrather, 2011; Saijo and Glass, 2011). We reported that MST1 mediates oxidative stress-induced cell death in mammalian primary neurons (Lehtinen et al., 2006), and c-Abl kinase phosphorylates MST1 at Y433 during oxidative stress-induced neuronal cell death (Xiao et al., 2011). Thus, we argue that tyrosine phosphorylation of MST1 at Y433 could be a marker of kinase activation.

Recently it has been demonstrated that MST1 plays a central role in the regulation of immune cell function (Du et al., 2014; Zhou et al., 2008), which led us to ask whether MST1 participates in microglial activation in CNS diseases. In the present study, we demonstrated that loss of MST1 protected against cerebral ischemia/reperfusion injury and neuro-inflammation. The novelties of our present work are as follows: 1) we demonstrated that MST1 acts as an essential protein kinase in stroke-induced microglial activation; 2) we defined IKBa as a substrate of MST1 during microglial activation and elucidated that MST1-IKBa signaling is important for NF-kB activation; 3) we further identified that Src kinase functions upstream of MST1-IKB signaling in microglia; 4) the deletion of MST1 in microglia mitigated microglial activation and neuronal cell death, thereby protecting against ischemic stroke. Together, we demonstrated that Src-MST1-IKB signaling plays a critical role in stroke-induced microglial activation, indicating that MST1 could represent a potent therapeutic target for ischemic stroke (as described in Figure $6 \mathrm{H}$ ).

First, we found the MST1 is involved in ischemia-induced microglial activation and inflammation. Similar to our finding, microglial cells release TNF- $\alpha$, IL-6, NO and IL- $1 \beta$ upon activation by brain damage (Liesz et al., 2009). Numerous studies have also demonstrated microglial activation by examining the mRNA levels of TNF-alpha, IL-6 and IL-1beta in the brain (Liesz et al., 2009; Shao et al., 2013). We have repeatedly attempted to assess the protein levels of TNF-alpha and IL-6 by 
ELISA. However, we failed to detect the positive signals in our experimental system. Furthermore, in MCAO models, we observed that MST1 deficiency in microglia reduced the number of Iba-1/CD-11b-positive cells compared with the control (Figure 5E and 5F). Therefore, we believe that the mRNA levels of TNF- $\alpha$ and IL-6 together with the increase in Iba-1/CD11b staining strongly indicate microglial activation.

In this study, we found that the phosphorylation of MST1 at Y433 was significantly increased upon stimulation by LPS, OGD, or cerebral ischemia. Importantly, we identified Src kinase as an upstream activator of MST1 by candidate screening during microglial activation and found that Src inhibition reduced MST1 Y433 phosphorylation in vitro and in vivo. Previously, it has been reported that treatment with a Src kinase inhibitor (PP2) or Src deficiency protects against stroke damage (Lennmyr et al., 2004). Consistently, in our study, the inhibition of Src activation with AZD0530 protected against cerebral ischemia. However, whether AZD0530 could be used for the treatment of ischemia/reperfusion related diseases remains to be determined. Since AZD0530 confers non-specific inhibition on the other tyrosine kinases, the high specificity of Src inhibitor needs to be improved to this end.

Increasing evidence shows that NF-kB plays a key role in ischemic stroke (Schwaninger et al., 2006). Cerebral ischemia leads to NF-KB activation in neurons, astrocytes, microglia, and infiltrating inflammatory cells (Kaushal and Schlichter, 2008; Kuboyama et al., 2011; Nurmi et al., 2004; Schneider et al., 1999; Stephenson et al., 2000). The inhibition of IKK activity in neurons markedly reduced the infarct size following MCAO (Herrmann et al., 2005). Knockout of NF-kB subunit p50 also decreased the infarct size after MCAO (Schneider et al., 1999). NF-KB activation within a few hours after ischemic stroke promotes a series of molecular events that leads to neuroinflammation, primarily caused by excessive numbers of activated microglia and infiltrating T cells. Recent studies have suggested potential crosstalk between MST1 and NF-KB in cardiac fibroblasts (Odashima et al., 2007) and in HeLa cells (Wong et al., 2009). Odashima et al reported that proinflammatory cytokines were significantly attenuated in Tg-DN-Mst1 (domain negative MST1-K59R) mice in a myocardial infarction model (Odashima et al., 2007). However, the crosstalk between MST1 and NF-KB signaling 
in neuroinflammation has not been clearly revealed. Microglia are a major producer of TNF, which is an essential effector in cerebral ischemia and brain inflammation (Lambertsen et al., 2009). Here, we found that MST1 deletion inhibited TNF- $\alpha$ and IL-6 release following stimulation by OGD or LPS in microglial cells, and these effects were rescued by MST1 overexpression. Importantly, we are the first to report that MST1 phosphorylates $1 \mathrm{~KB} \alpha$ at $\mathrm{S} 32 / 36$, promotes $\mathrm{I} \mathrm{KB} \alpha$ degradation and inhibits NF-KB activation in microglial cells. Taken together, our data strongly support the model that IKBa acts downstream of MST1 during microglial activation. Interestingly, the effect of MST1 on NF-KB activation in different cell types remains controversial. Wong et al reported that MST1 knockdown promoted the nuclear entry of NF-kB-p65 and apoptosis in HeLa cells (Wong et al., 2009). Therefore, MST1-NF-KB signaling might behave differently in different cell types, and this needs to be further investigated.

Our data strongly suggest that the specific deletion of MST1 inhibits microglial activation and reduces cerebral ischemic injury. We observed a reduced number of activated microglia in Lyz2cre:Mst1 $1^{\text {f/f }}$ mice upon ischemia and reperfusion. However, Lyz2 is also expressed in macrophage, bone marrow and lymph nodes, but not in the brain vasculature. Lyz2Cre:Mst1f/f mice only deleted MST1 in microglial cells in brain, not vascular tissues. Therefore, we argue that the brain vasculature in Lyz2Cre:Mst1f/f mice might not be affected. Furthermore, in Lyz2cre:Mst1/f mice, MST1 should be deleted in both microglia and macrophages. Macrophage infiltration in the CNS exacerbates ischemia-induced brain injury and macrophage inhibition enhances neuroprotection (Tang et al., 2014). The biological effect of MST1 in macrophages and monocytes under brain ischemic oxidative stress must be further studied.

AZD0530 has been identified in cerebrospinal fluid (CSF) from patients treated with this Src inhibitor (Nygaard et al., 2015), which indicates that AZD0530 can penetrate the blood-brain barrier (BBB). In addition, the permeability of the BBB is increased upon ischemia (Engelhardt and Sorokin, 2009; Sairanen et al., 1997; Strbian et al., 2006). Similarly, we observed a significant reduction of Src active phosphorylation in brain samples afer intraperitoneal administration of AZD0530. Together, these findings indicate that AZD0530 could penetrate the BBB in MCAO models. However, AZD0530 
might inhibit other kinases in addition to Src, such as Lck, C-YES, Lyn, Fyn, Fgr and Blk. It has been shown that AZD0530 effectively reduces Src kinase activity in non-small cell lung cancer and colorectal cancer (Chua et al., 2015; Reddy et al., 2015). Moreover, our screening results in Figure 3A showed that only Src and Tnk2, but not other tyrosine kinases (Lck, c-YES, Lyn, Fyn, Fgr and Blk), functioned as the possible upstream kinases of pY433-MST1. Together, we argue that AZD0530-mediated inhibition of Src, but not the other AZD0530 non-specific target kinases, decreased MST1 phosphorylation and activation in MCAO mice. Furthermore, we found that 10 $\mathrm{mg} / \mathrm{kg}$ of AZD0530 in mice effectively reduced infarct volume and neurological score after extensive titration $(1,5$ and $10 \mathrm{mg} / \mathrm{kg})$ in animals. The $\mathrm{IC}_{50}(2.7-11 \mathrm{nM})$ used to inhibit the kinases listed above has been determined in vitro. According to the product information from the Selleck Company, a range of concentrations is used both in cells and in mice $(62.5 \mathrm{nM}-16 \mathrm{mM}$ in cells and $25 \mathrm{mg} / \mathrm{kg}$ in mice). Therefore, we chose $10 \mathrm{mg} / \mathrm{kg}$ of AZD0530 in our experiments.

In summary, our present findings suggest that MST1 is associated with microglial activation stimulated by LPS, OGD, or ischemic stroke. Together with our previous findings (Xiao et al., 2011), we argue that phosphorylation of MST1 at Y433 plays a crucial role in both neuronal cell death and microglial activation upon oxidative stress. Therefore, the administration of an MST1-specific inhibitor might be useful for the treatment of ischemic diseases by targeting these two cell types in the CNS. 


\section{Acknowledgements}

This work was supported by the National Science Foundation of China (Grant No. 81125010 and 81030025), the National Basic Research Program of China (973-2012CB910701 and 2013DFA31990), and Cross-disciplinary Collaborative Teams Program for Science, Technology and Innovation (2014-2016) from Chinese Academy of Sciences.

\section{References}

Burguillos, M.A., Svensson, M., Schulte, T., Boza-Serrano, A., Garcia-Quintanilla, A., Kavanagh, E., Santiago, M., Viceconte, N., Oliva-Martin, M.J., Osman, A.M., Salomonsson, E., Amar, L., Persson, A., Blomgren, K., Achour, A., Englund, E., Leffler, H., Venero, J.L., Joseph, B., Deierborg, T., 2015. Microglia-Secreted Galectin-3 Acts as a Toll-like Receptor 4 Ligand and Contributes to Microglial Activation. Cell Rep.

Chang, J.Y., Chavis, J.A., Liu, L.Z., Drew, P.D., 1998. Cholesterol oxides induce programmed cell death in microglial cells. Biochem Biophys Res Commun 249, 817-821.

Chong, Z.Z., Li, F., Maiese, K., 2005. Oxidative stress in the brain: novel cellular targets that govern survival during neurodegenerative disease. Prog Neurobiol 75, 207-246.

Chua, K.N., Kong, L.R., Sim, W.J., Ng, H.C., Ong, W.R., Thiery, J.P., Huynh, H., Goh, B.C., 2015. Combinatorial treatment using targeted MEK and SRC inhibitors synergistically abrogates tumor cell growth and induces mesenchymal-epithelial transition in non-small-cell lung carcinoma. Oncotarget.

Csibi, A., Blenis, J., 2012. Hippo-YAP and mTOR pathways collaborate to regulate organ size. Nat Cell Biol 14, 1244-1245.

Davalos, D., Grutzendler, J., Yang, G., Kim, J.V., Zuo, Y., Jung, S., Littman, D.R., Dustin, M.L., Gan, W.B., 2005. ATP mediates rapid microglial response to local brain injury in vivo. Nat Neurosci 8, 752-758.

Del Re, D.P., Matsuda, T., Zhai, P., Maejima, Y., Jain, M.R., Liu, T., Li, H., Hsu, C.P., Sadoshima, J., 2014. Mst1 promotes cardiac myocyte apoptosis through phosphorylation and inhibition of $\mathrm{BCl}-\mathrm{xL}$. Mol Cell 54, 639-650.

Di, X., Bullock, R., Watson, J., Fatouros, P., Chenard, B., White, F., Corwin, F., 1997. Effect of CP101,606, a novel NR2B subunit antagonist of the $\mathrm{N}$-methyl-D-aspartate receptor, on the volume of ischemic brain damage off cytotoxic brain edema after middle cerebral artery occlusion in the feline brain. Stroke 28, 2244-2251.

Du, X., Shi, H., Li, J., Dong, Y., Liang, J., Ye, J., Kong, S., Zhang, S., Zhong, T., Yuan, Z., Xu, T., Zhuang, Y., Zheng, B., Geng, J.G., Tao, W., 2014. Mst1/Mst2 regulate development and function of regulatory T cells through modulation of Foxo1/Foxo3 stability in autoimmune disease. J Immunol 192, 1525-1535.

Ducis, I., Norenberg, L.O., Norenberg, M.D., 1990. The benzodiazepine receptor in cultured astrocytes from genetically epilepsy-prone rats. Brain Res 531, 318-321.

Engelhardt, B., Sorokin, L., 2009. The blood-brain and the blood-cerebrospinal fluid barriers: function and dysfunction. Semin Immunopathol 31, 497-511.

Finkel, T., 2000. Redox-dependent signal transduction. FEBS Lett 476, 52-54.

Gaudilliere, B., Shi, Y., Bonni, A., 2002. RNA interference reveals a requirement for myocyte enhancer factor $2 \mathrm{~A}$ in activity-dependent neuronal survival. J Biol Chem 277, 46442-46446.

Goldlust, E.J., Paczynski, R.P., He, Y.Y., Hsu, C.Y., Goldberg, M.P., 1996. Automated measurement of infarct size with scanned images of triphenyltetrazolium chloride-stained rat brains. Stroke 27, 1657-1662.

Hara, H., Huang, P.L., Panahian, N., Fishman, M.C., Moskowitz, M.A., 1996. Reduced brain edema and infarction volume in mice lacking the neuronal isoform of nitric oxide synthase after transient MCA occlusion. J Cereb Blood Flow Metab 16, 
605-611.

Herrmann, O., Baumann, B., de Lorenzi, R., Muhammad, S., Zhang, W., Kleesiek, J., Malfertheiner, M., Kohrmann, M., Potrovita, I., Maegele, I., Beyer, C., Burke, J.R., Hasan, M.T., Bujard, H., Wirth, T., Pasparakis, M., Schwaninger, M., 2005. IKK mediates ischemia-induced neuronal death. Nat Med 11, 1322-1329.

Iadecola, C., Anrather, J., 2011. The immunology of stroke: from mechanisms to translation. Nat Med 17, 796-808.

Kaushal, V., Schlichter, L.C., 2008. Mechanisms of microglia-mediated neurotoxicity in a new model of the stroke penumbra. J Neurosci 28, 2221-2230.

Kim, J.H., Lee, S.H., Sohn, H.J., Lee, J., Chwae, Y.J., Park, S., Kim, K., Shin, H.J., 2012. The immune response induced by DNA vaccine expressing nfa1 gene against Naegleria fowleri. Parasitol Res 111, 2377-2384.

Kuboyama, K., Harada, H., Tozaki-Saitoh, H., Tsuda, M., Ushijima, K., Inoue, K., 2011. Astrocytic P2Y(1) receptor is involved in the regulation of cytokine/chemokine transcription and cerebral damage in a rat model of cerebral ischemia. J Cereb Blood Flow Metab 31, 1930-1941.

Lambertsen, K.L., Clausen, B.H., Babcock, A.A., Gregersen, R., Fenger, C., Nielsen, H.H., Haugaard, L.S., Wirenfeldt, M., Nielsen, M., Dagnaes-Hansen, F., Bluethmann, H., Faergeman, N.J., Meldgaard, M., Deierborg, T., Finsen, B., 2009. Microglia protect neurons against ischemia by synthesis of tumor necrosis factor. J Neurosci 29, 1319-1330.

Lange, A.W., Sridharan, A., Xu, Y., Stripp, B.R., Perl, A.K., Whitsett, J.A., 2015. Hippo/Yap signaling controls epithelial progenitor cell proliferation and differentiation in the embryonic and adult lung. J Mol Cell Biol 7, 35-47.

Lehtinen, M.K., Yuan, Z., Boag, P.R., Yang, Y., Villen, J., Becker, E.B., DiBacco, S., de la Iglesia, N., Gygi, S., Blackwell, T.K., Bonni, A., 2006. A conserved MST-FOXO signaling pathway mediates oxidative-stress responses and extends life span. Cell 125, 987-1001.

Lennmyr, F., Ericsson, A., Gerwins, P., Akterin, S., Ahlstrom, H., Terent, A., 2004. Src family kinase-inhibitor PP2 reduces focal ischemic brain injury. Acta Neurol Scand 110, 175-179.

Liesz, A., Suri-Payer, E., Veltkamp, C., Doerr, H., Sommer, C., Rivest, S., Giese, T., Veltkamp, R., 2009. Regulatory T cells are key cerebroprotective immunomodulators in acute experimental stroke. Nat Med 15, 192-199.

Mi, W., Lin, Q., Childress, C., Sudol, M., Robishaw, J., Berlot, C.H., Shabahang, M., Yang, W., 2014. Geranylgeranylation signals to the Hippo pathway for breast cancer cell proliferation and migration. Oncogene.

Nurmi, A., Lindsberg, P.J., Koistinaho, M., Zhang, W., Juettler, E., Karjalainen-Lindsberg, M.L., Weih, F., Frank, N., Schwaninger, M., Koistinaho, J., 2004. Nuclear factor-kappaB contributes to infarction after permanent focal ischemia. Stroke 35, 987-991.

Nygaard, H.B., Wagner, A.F., Bowen, G.S., Good, S.P., MacAvoy, M.G., Strittmatter, K.A., Kaufman, A.C., Rosenberg, B.J., Sekine-Konno, T., Varma, P., Chen, K., Koleske, A.J., Reiman, E.M., Strittmatter, S.M., van Dyck, C.H., 2015. A phase Ib multiple ascending dose study of the safety, tolerability, and central nervous system availability of AZD0530 (saracatinib) in Alzheimer's disease. Alzheimers Res Ther 7, 35.

Odashima, M., Usui, S., Takagi, H., Hong, C., Liu, J., Yokota, M., Sadoshima, J., 2007. Inhibition of endogenous Mst1 prevents apoptosis and cardiac dysfunction without affecting cardiac hypertrophy after myocardial infarction. Circ Res 100, $1344-1352$.

Pan, X.D., Chen, X.C., Zhu, Y.G., Zhang, J., Huang, T.W., Chen, L.M., Ye, Q.Y., Huang, H.P., 2008. Neuroprotective role of tripchlorolide on inflammatory neurotoxicity induced by lipopolysaccharide-activated microglia. Biochem Pharmacol 76, 362-372.

Reddy, S.M., Kopetz, S., Morris, J., Parikh, N., Qiao, W., Overman, M.J., Fogelman, D., Shureiqi, I., Jacobs, C., Malik, Z., Jimenez, C.A., Wolff, R.A., Abbruzzese, J.L., Gallick, G., Eng, C., 2015. Phase II study of saracatinib (AZD0530) in patients with previously treated metastatic colorectal cancer. Invest New Drugs 33, 977-984.

Saijo, K., Glass, C.K., 2011. Microglial cell origin and phenotypes in health and disease. Nat Rev Immunol 11, 775-787.

Sairanen, T.R., Lindsberg, P.J., Brenner, M., Siren, A.L., 1997. Global forebrain ischemia results in differential cellular expression of interleukin-1beta (IL-1beta) and its receptor at mRNA and protein level. J Cereb Blood Flow Metab 17, 1107-1120.

Schilling, M., Besselmann, M., Muller, M., Strecker, J.K., Ringelstein, E.B., Kiefer, R., 2005. Predominant phagocytic activity of 
resident microglia over hematogenous macrophages following transient focal cerebral ischemia: an investigation using green fluorescent protein transgenic bone marrow chimeric mice. Exp Neurol 196, 290-297.

Schneider, A., Martin-Villalba, A., Weih, F., Vogel, J., Wirth, T., Schwaninger, M., 1999. NF-kappaB is activated and promotes cell death in focal cerebral ischemia. Nat Med 5, 554-559.

Schwaninger, M., Inta, I., Herrmann, O., 2006. NF-kappaB signalling in cerebral ischaemia. Biochem Soc Trans 34, $1291-1294$. Shao, W., Zhang, S.Z., Tang, M., Zhang, X.H., Zhou, Z., Yin, Y.Q., Zhou, Q.B., Huang, Y.Y., Liu, Y.J., Wawrousek, E., Chen, T., Li, S.B., $\mathrm{Xu}$, M., Zhou, J.N., Hu, G., Zhou, J.W., 2013. Suppression of neuroinflammation by astrocytic dopamine D2 receptors via alphaB-crystallin. Nature 494, 90-94.

Socodato, R., Portugal, C.C., Domith, I., Oliveira, N.A., Coreixas, V.S., Loiola, E.C., Martins, T., Santiago, A.R., Paes-de-Carvalho, R., Ambrosio, A.F., Relvas, J.B., 2015. c-Src function is necessary and sufficient for triggering microglial cell activation. Glia 63, 497-511.

Stephenson, D., Yin, T., Smalstig, E.B., Hsu, M.A., Panetta, J., Little, S., Clemens, J., 2000. Transcription factor nuclear factor-kappa B is activated in neurons after focal cerebral ischemia. J Cereb Blood Flow Metab 20, 592-603.

Strbian, D., Karjalainen-Lindsberg, M.L., Tatlisumak, T., Lindsberg, P.J., 2006. Cerebral mast cells regulate early ischemic brain swelling and neutrophil accumulation. J Cereb Blood Flow Metab 26, 605-612.

Tang, Z., Gan, Y., Liu, Q., Yin, J.X., Liu, Q., Shi, J., Shi, F.D., 2014. CX3CR1 deficiency suppresses activation and neurotoxicity of microglia/macrophage in experimental ischemic stroke. J Neuroinflammation 11, 26.

Umemura, K., Kato, I., Hirashima, Y., Ishii, Y., Inoue, T., Aoki, J., Kono, N., Oya, T., Hayashi, N., Hamada, H., Endo, S., Oda, M., Arai, H., Kinouchi, H., Hiraga, K., 2007. Neuroprotective role of transgenic PAF-acetylhydrolase II in mouse models of focal cerebral ischemia. Stroke 38, 1063-1068.

Venna, V.R., Weston, G., Benashski, S.E., Tarabishy, S., Liu, F., Li, J., Conti, L.H., McCullough, L.D., 2012. NF-kappaB contributes to the detrimental effects of social isolation after experimental stroke. Acta Neuropathol 124, 425-438.

Wong, C.H., Chan, H., Ho, C.Y., Lai, S.K., Chan, K.S., Koh, C.G., Li, H.Y., 2009. Apoptotic histone modification inhibits nuclear transport by regulating RCC1. Nat Cell Biol 11, 36-45.

Wu, L.J., Wu, G., Akhavan Sharif, M.R., Baker, A., Jia, Y., Fahey, F.H., Luo, H.R., Feener, E.P., Clapham, D.E., 2012. The voltage-gated proton channel Hv1 enhances brain damage from ischemic stroke. Nat Neurosci 15, 565-573.

Wu, R., Chen, H., Ma, J., He, Q., Huang, Q., Liu, Q., Li, M., Yuan, Z., 2015. c-Abl-p38alpha signaling plays an important role in MPTP-induced neuronal death. Cell Death Differ.

Xiao, L., Chen, D., Hu, P., Wu, J., Liu, W., Zhao, Y., Cao, M., Fang, Y., Bi, W., Zheng, Z., Ren, J., Ji, G., Wang, Y., Yuan, Z., 2011. The c-Abl-MST1 signaling pathway mediates oxidative stress-induced neuronal cell death. J Neurosci 31, 9611-9619.

Yuan, Z., Kim, D., Shu, S., Wu, J., Guo, J., Xiao, L., Kaneko, S., Coppola, D., Cheng, J.Q., 2010. Phosphoinositide 3-kinase/Akt inhibits MST1-mediated pro-apoptotic signaling through phosphorylation of threonine 120. J Biol Chem 285, 3815-3824.

Zhang, W., Potrovita, I., Tarabin, V., Herrmann, O., Beer, V., Weih, F., Schneider, A., Schwaninger, M., 2005. Neuronal activation of NF-kappaB contributes to cell death in cerebral ischemia. J Cereb Blood Flow Metab 25, 30-40.

Zhou, D., Medoff, B.D., Chen, L., Li, L., Zhang, X.F., Praskova, M., Liu, M., Landry, A., Blumberg, R.S., Boussiotis, V.A., Xavier, R., Avruch, J., 2008. The Nore1B/Mst1 complex restrains antigen receptor-induced proliferation of naive T cells. Proc Natl Acad Sci U S A 105, 20321-20326. 


\section{Figure Legends}

Figure 1 The function of MST1 in activated microglia in vivo and in vitro. (A) TTC staining of coronal brain sections from freeze brains $(n=3)$ and fresh brains $(n=3) 24$ h after tMCAO under enflurane anesthesia in C57bl/6 mice. (B-F) Mst1 ${ }^{-\%}$ mice and corresponding wild-type mice were subjected to MCAO for $1 \mathrm{~h}$ followed by reperfusion for $24 \mathrm{~h}$. (B) TTC staining of coronal brain sections from wild-type $(n=7)$ and $M s t 1^{-/}$mice $(n=7) 24 \mathrm{~h}$ after tMCAO under enflurane anesthesia. (C) The infarct volume was reduced from $29.75 \pm 1.78 \%$ of the entire brain in wild-type mice to $10.70 \pm 1.46 \%$ in $\mathrm{Mst1}^{-/}$mice. The data are presented as the mean $\pm \mathrm{SEM} ; \mathrm{n}=7$. ${ }^{* * *} \mathrm{P}<0.001$ compared with the wild-type group using Student's $t$-test. (D) The neurological scores after tMCAO revealed less neurological impairment in $M s t 1^{-1-}$ mice $(n=7)$ than in wild-type mice $(n=7)$. ${ }^{*} P<0.05$ (MannWhitney $U$ test). (E) Images of immunostaining for CD11b, a marker of microglial cells, in the striatal region; $n=3$. (F) The number of cells expressing CD11b $\left(C D 11 b^{+}\right)$in the ischemic striatum (across the confocal microscopic field of serial sections under $400 \times$ magnification). ${ }^{* *} \mathrm{P}<0.01$. (G) The TNF- $\alpha$ and $I L-6$ mRNA levels in the infarct area of $M s t 1^{-/}$mice $(n=3)$ were reduced compared with wild-type mice $(n=3) .{ }^{*} P<0.05 ;{ }^{* *} P<0.01$. (H) The cell viability of primary microglial cells from wild-type and MST1 knockout mice detected by MTT. (I) The secretion of TNF- $\alpha$ and IL-6 by control or OGD-treated primary microglia from $\mathrm{Mst}^{-\%}$ or $\mathrm{Mst}^{+/+}$mice was assessed by ELISA. (J) The secretion of TNF- $\alpha$ and IL-6 by control or LPS-treated primary microglia from $\mathrm{Mst}^{-1 /}$ or $\mathrm{Mst1}^{+/+}$mice was assessed by ELISA.

Figure 2 The phosphorylation of MST1 at tyrosine 433 (Y433) is involved in microglial activation. Phosphorylated MST1 at Y433 in mouse BV2 cells (A), mouse primary microglia (B), and ischemic striatum (C) were detected by Western blot. Quantification of the relative band intensities was performed by densitometry. Each bar represents the mean \pm SEM of three independent experiments. $\left({ }^{* * *} \mathrm{P}<0.001\right)$. (D) Images of immunostaining for Iba-1 and $\mathrm{p}-\mathrm{Y} 433 \mathrm{MST} 1$ and $(\mathrm{E})$ quantification of the p-Y433 MST1 levels in LPS-stimulated microglia. The TNF- $\alpha(\mathbf{F})$ and IL-6 (G) mRNA levels in primary microglia that were transduced with Flag-wild-type MST1 or Flag-MST1-Y433F and were stimulated by LPS for $6 \mathrm{~h}$ as detected by qPCR. ${ }^{* * *} \mathrm{P}<0.001$ compared with the Flag-MST1-overexpressing 
group (ANOVA followed by a Bonferroni multiple comparisons test).

Figure 3 Src acts as an upstream regulator of MST1 to activate microglia. (A) The screening model upstream of MST1. (B) Lysates of HEK 293T cells transfected with Myc-tagged Src-WT or Src-KD were immunoprecipitated with an anti-Myc antibody and subjected to an in vitro kinase assay using full-length GST-MST1 or GST-MST1-Y433F as a substrate. The phosphorylation reactions were analyzed by immunoblotting using antibodies against p-Y433-MST1, MST1, and Myc. MST1 was tyrosine phosphorylated by Src kinase in vitro. (C) Lysates of HEK 293T cells transfected with Flag-tagged MST1 alone or together with a Myc-tagged Src-WT or Src-KD expression plasmid were immunoprecipitated using an anti-Flag antibody and were analyzed by immunoblotting using a tyrosine-phosphorylation specific antibody against $\mathrm{p}-\mathrm{Y} 433-\mathrm{MST1}$ and antibodies against MST1, Flag, GAPDH, and Myc. (D) Stably Src-silenced BV2 cells and control cells were treated with LPS (1 $\mathrm{gg} / \mathrm{ml})$ for $1 \mathrm{~h}$. The phosphorylation of MST1 at Y433 was detected by Western blot. (E) Primary microglia were treated with AZD0530 $(0.5 \mu \mathrm{M})$ for $2 \mathrm{~h}$ during stimulation by OGD. Western blots were performed to assess the levels of total MST1 and of MST phosphorylated at Y433. (F) BV2 cells were pretreated with AZD0530 $(0.5 \mu \mathrm{M})$ following stimulation with LPS $(1 \mu \mathrm{g} / \mathrm{ml})$ for $1 \mathrm{~h}$. Western blots were performed to assess the levels of $\mathrm{p}$-Y433-MST1 at Y433, the p-Src, MST1, and Src. (G) The cell viability of AZD0530 treatment in BV2 cells by MTT detecting. $(\mathbf{H})$ Primary microglia were treated with AZD0530 (0.5 $\mu \mathrm{M})$ following stimulation by OGD. The secretion of TNF- $\alpha$ into the supernatant of mouse primary microglia was assessed by ELISA. ${ }^{* * *} \mathrm{P}<0.001$ compared with the OGD group (unpaired $t$-test). (I) Primary microglia were treated with AZD0530 $(0.5 \mu \mathrm{M})$ following stimulation with LPS $(1 \mu \mathrm{g} / \mathrm{ml})$ for $24 \mathrm{~h}$. The secretion of TNF- $\alpha$ in the supernatant of mouse primary microglia was assessed by ELISA. ${ }^{* *} \mathrm{P}<0.001$ compared with the LPS group (unpaired $t$-test). (J) BV2 cells stably overexpressing Src-WT or Src-KD alone or together with MST1-WT or MST1-Y433F were treated with LPS $(1 \mu \mathrm{g} / \mathrm{ml})$ for $24 \mathrm{~h}$. Immunoblot analyses of iNOS, Src, MST1, and $\beta$-actin expression are shown.

Figure 4 Regulation of NF-KB signaling by MST1. (A) Immunoblot analysis of the phosphorylation of $\mathrm{IKB} \alpha$ in primary microglia from wild-type and $\mathrm{MST}^{-1-}$ mice. (B) Quantification of the relative band 
intensities was performed by densitometry. Each bar represents the mean \pm SEM of three independent experiments ( $\left.{ }^{\star} \mathrm{P}<0.05\right)$. (C) Full-length GST-MST1, GST-IkBa-WT, and GST-IKBa-S32/36A were used as substrates in the in vitro kinase assay. The phosphorylation reactions were analyzed by

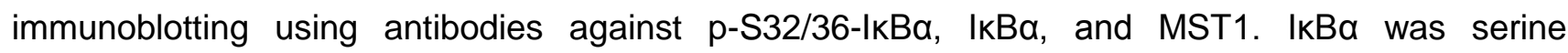
phosphorylated by MST1 kinase in vitro. (D) Lysates of HEK 293T cells transfected with GFP-tagged MST1 alone or together with the Flag-tagged IKBa-WT or Flag-tagged IkBa-S32/36A expression plasmid were immunoprecipitated using an anti-Flag antibody and analyzed by immunoblotting using antibodies against p-S32/36-IKBa, Flag, and GFP. (E) BV2 cells stably overexpressing MST1-WT or MST1-KD alone or together with IKBa-WT or IKBa-S32/36A were treated with LPS $(1 \mu \mathrm{g} / \mathrm{ml})$ for $24 \mathrm{~h}$. Immunoblot analyses of iNOS, IKBa, MST1, and $\beta$-actin expression are shown. (F) Quantification of the relative band intensities was performed by densitometry. (G) BV2 cells stably overexpressing MST1-WT alone or together with p65 siRNA were treated with or without LPS $(1 \mu \mathrm{g} / \mathrm{ml})$ for $24 \mathrm{~h}$. The secretion of TNF- $\alpha$ was assessed by ELISA. (H) Primary microglial cells from wild type or MST1 knockout mice were cultured in 24-well plates and transfected with $0.5 \mu \mathrm{g} /$ well pNFkB-luc reporter construct and $10 \mathrm{ng} /$ well pRL-TK construct. The cells were then cultured in the presence or absence of LPS $(1 \mu \mathrm{g} / \mathrm{ml})$ for $12 \mathrm{~h}$. The relative promoter activity was presented as percent increase in stimulated cells vs untreated cells. Each bar represents the mean \pm SEM of three independent experiments $\left({ }^{*} \mathrm{P}<0.05,{ }^{* *} \mathrm{P}<0.01\right.$ and $\left.{ }^{* *} \mathrm{P}<0.001\right)$.

Figure 5 Loss of MST1 in microglia/macrophages protects against cerebral ischemia-induced brain injury. (A) TTC staining of coronal brain sections from Mst $1^{\text {t/f }}(\mathrm{n}=7)$ or Lyz2cre:Mst $1^{\text {t/f }}$ mice $(\mathrm{n}=7) 24 \mathrm{~h}$ after tMCAO under enflurane anesthesia. (B) The infarct volume was reduced from $31.29 \pm 3.65 \%$ of the total brain volume in the $M s t 1^{1 / f}$ mice to $17.14 \pm 2.65 \%$ in the Lyz2cre:Mst $1^{\mathrm{ft/}}$ mice. The data are presented as the mean \pm SEM; $n=7 .{ }^{* *} \mathrm{P}<0.01$ compared with the wild-type group based on Student's $t$-test. (C) The neurological scores after tMCAO revealed less neurological impairment in the Lyz2cre:Mst ${ }^{f / f}$ mice $(n=11)$ than in the $M s t 1^{1 / f}$ mice $(n=12) .{ }^{* *} \mathrm{P}<0.01$ (Mann-Whitney $U$ test). (D) Immunoblot analysis of the expression of MST1 in primary microglia, neurons and astrocytes from $M s t 1^{t / f}$ and Lyz2cre:Mst $1^{\mathrm{f} / \mathrm{f}}$ mice. (E) Images of immunostaining for Iba-1 in an ischemic striatal 
subregion; $n=3$. (F) Number of cells expressing lba-1 (lba-1+) in striatal region (across the confocal microscopic field of serial sections under $400 \times$ magnification). ${ }^{* *} \mathrm{P}<0.01$ (unpaired $t$-test). (G) NeuN and TUNEL immunostaining of the infarcted striatum from Lyz2cre:Mst $1^{1 / f}$ mice $(n=5)$ and Mst $1^{t / f}$ mice $(\mathrm{n}=3) 24 \mathrm{~h}$ after tMCAO. (H) Number of cells expressing NeuN in ischemic striatal region (across the confocal microscopic field of serial sections under $400 \times$ magnification). ${ }^{* *} \mathrm{P}<0.01$ (unpaired $t$-test). (I) Quantification of TUNEL-positive cells after ischemic stroke in Lyz2cre:Mst $1^{1 / f}$ mice $(n=5)$ and $M s t 1^{f / f}$ mice $(\mathrm{n}=3) .{ }^{*} \mathrm{P}<0.05$ compared with the $M s t 1^{\mathrm{t} / \mathrm{f}}$ group (unpaired $t$-test). ( $\left.\mathrm{J}\right)$ Immunoblot analysis of the phosphorylated and total IKBa levels in the lysates of ischemic striatal subregions from Lyz2cre:Mst $1^{f / f}$ mice $(n=3)$ and $M s t 1^{f / f}$ mice $(n=3)$. (K) Quantification of the relative band intensities was performed by densitometry. Each bar represents the mean $\pm S E M$ of three independent experiments $\left({ }^{* * *} \mathrm{P}<0.001\right)$.

Figure 6 Inhibition of MST1 phosphorylation at Y433 using AZD0530 protected against ischemic stroke. (A) TTC staining of coronal brain section from the DMSO group $(n=7)$ and the AZD0530 group $(\mathrm{n}=8) 24 \mathrm{~h}$ after tMCAO under enflurane anesthesia. (B) The infarct volume was reduced from $25.91 \pm 4.29 \%$ of the total brain in the DMSO group to $10.84 \pm 2.10 \%$ in the AZD0530 group. The data are presented as the mean $\pm S E M ;{ }^{* *} \mathrm{P}<0.01$ compared with the DMSO group based on Student's $t$-test. (C) The neurological scores after tMCAO revealed less neurological impairment in the AZD0530 group $(n=8)$ than in the DMSO group $(n=7)$. ${ }^{*} P<0.05$ (Mann-Whitney $U$ test). (D) Immunoblot analysis of the levels of total IKBa, phosphorylated MST1 at Y433, phosphorylated Src, MST1, and Src in the lysates of ischemic striatal subregions in the DMSO group $(n=3)$ and the AZD0530 group $6 \mathrm{~h}$ after tMCAO under enflurane anesthesia $(n=3)$. (E) Images of immunostaining for Iba-1 in ischemic striatal subregions in the DMSO group $(\mathrm{n}=3)$ and the AZD0530 group $6 \mathrm{~h}$ after tMCAO under enflurane anesthesia $(n=3)$. (F) Number of cells expressing lba-1 $\left(\mathrm{lba}-1^{+}\right)$in the ischemic striatal region (across the confocal microscopic field of serial sections under $400 x$ magnification). ${ }^{* *} \mathrm{P}<0.01$ (unpaired $t$-test). (G) Quantification of the relative band intensities was performed by densitometry. Each bar represents the mean \pm SEM of three independent experiments ( $\left.{ }^{*} \mathrm{P}<0.05\right)$. (H) Model of the Src-MST1-IkBa signaling pathway. 
Figure 1

A

B

C

D

E
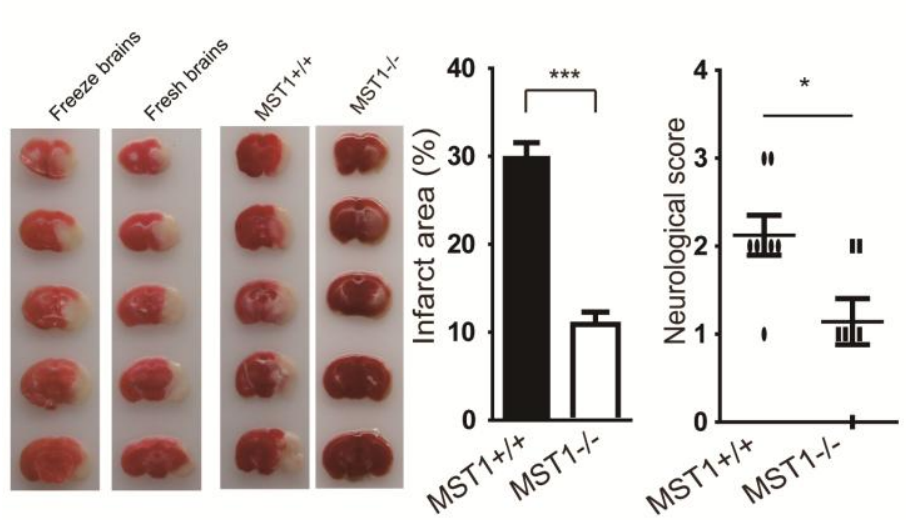

SHAM

MCAO

F

G

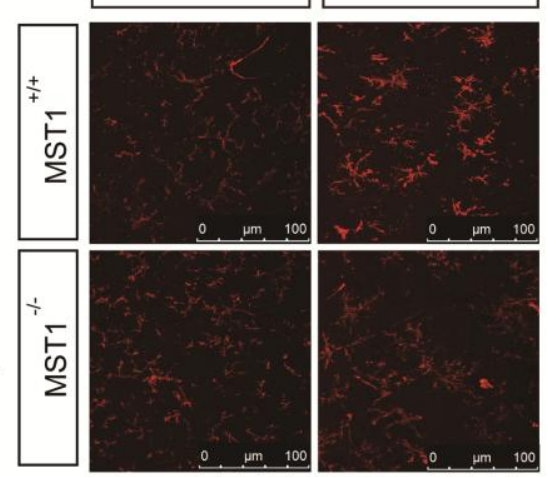

H

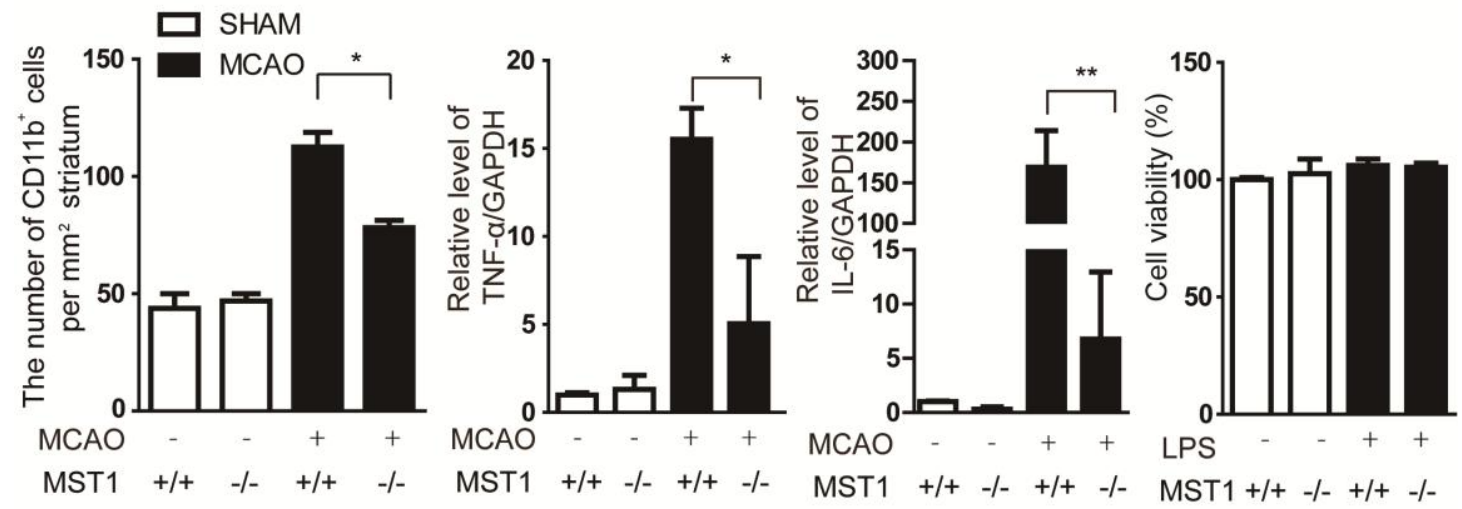

I
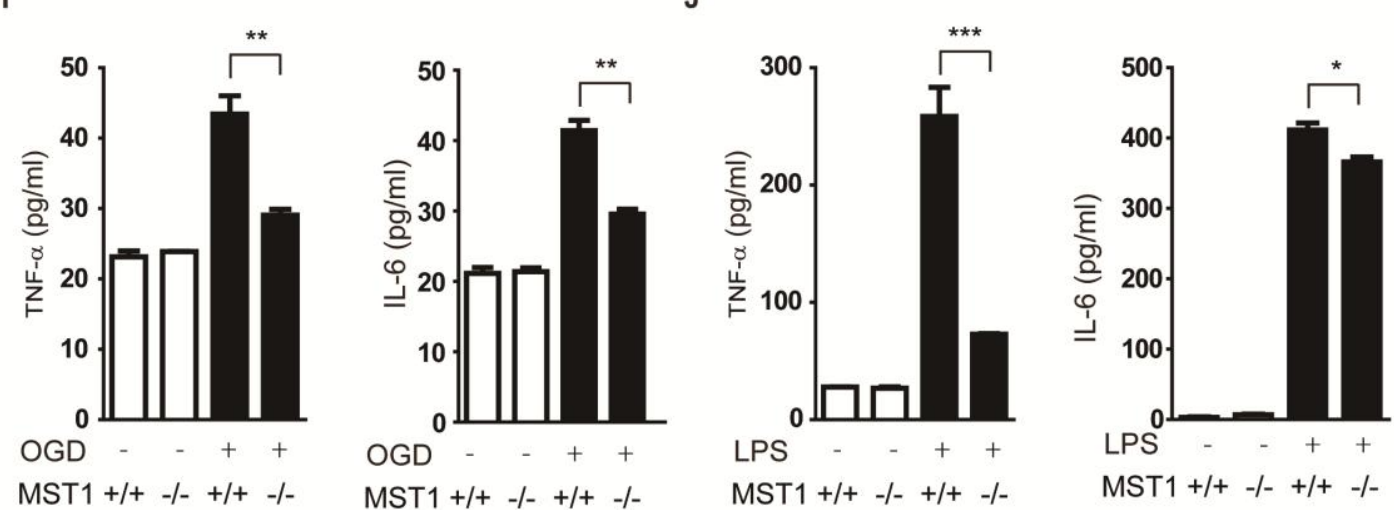
A

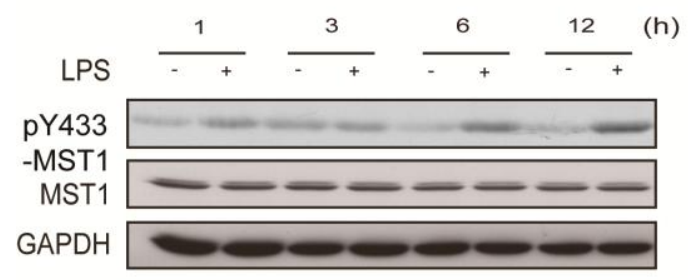

D

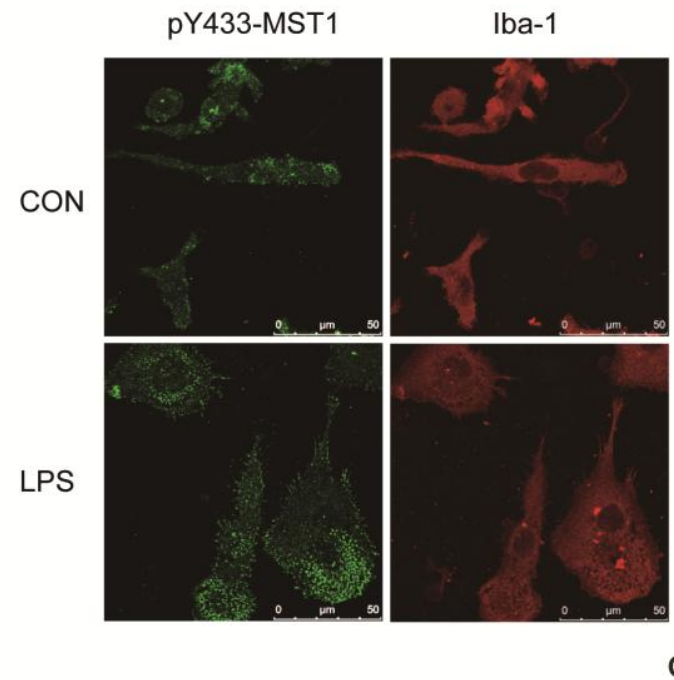

B

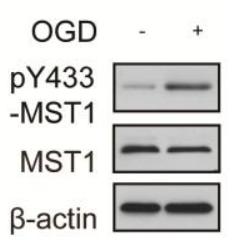

E

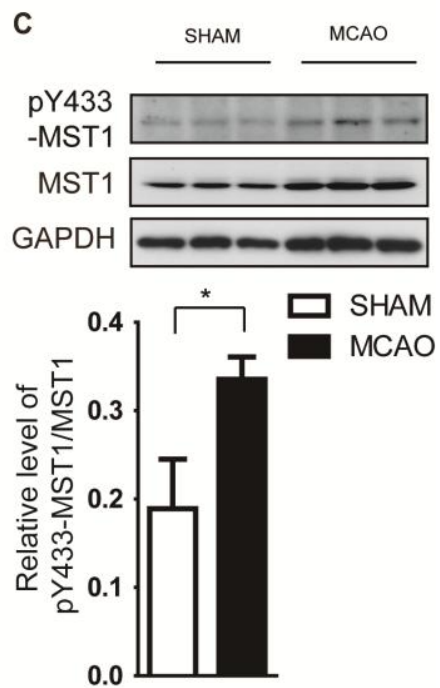

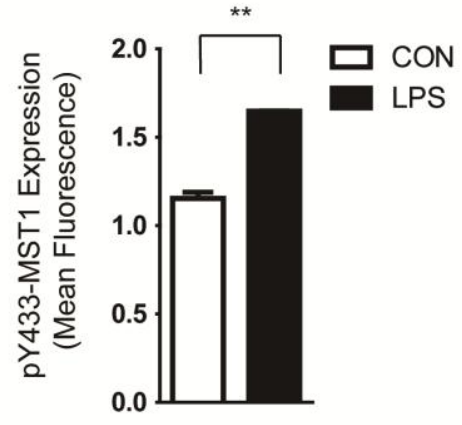

G

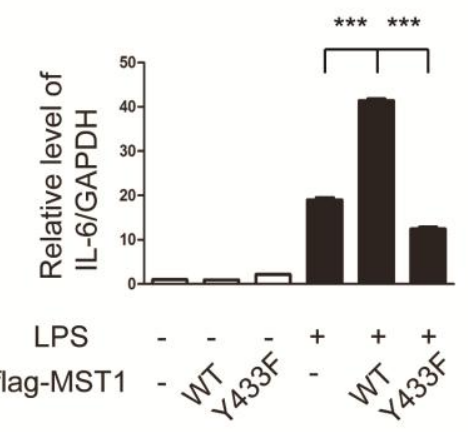


A

N9 microglial cells

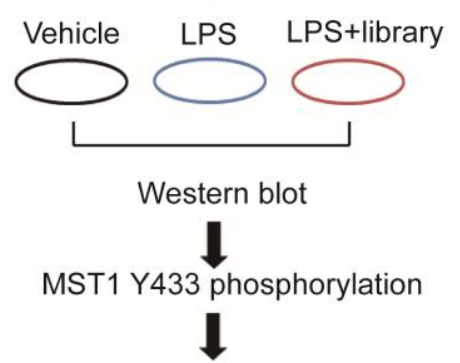

in vitro

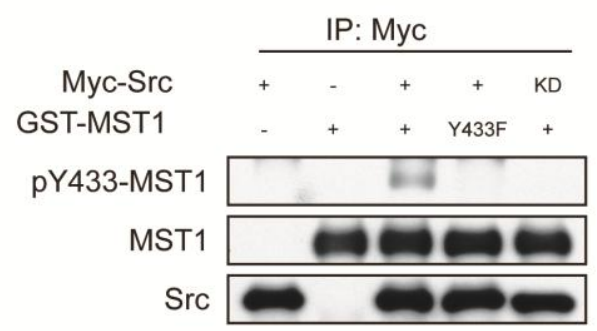

Screening out the tyrosine kinase Src and TNK2

C

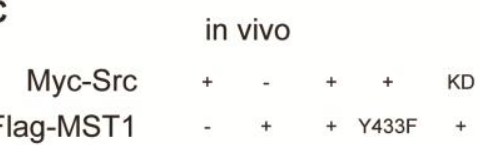

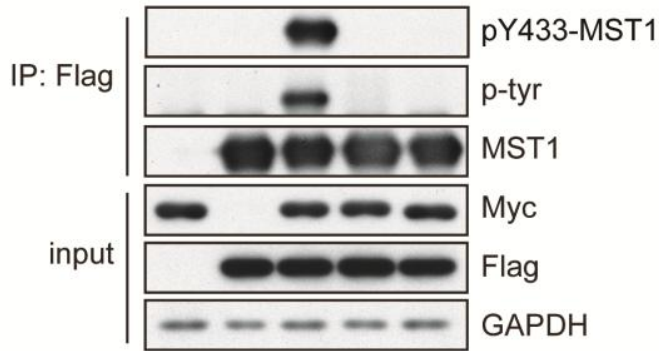

E

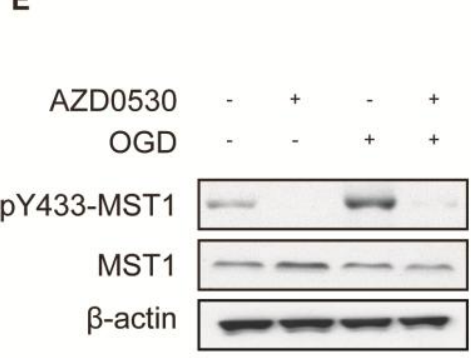

$\mathbf{F}$

D

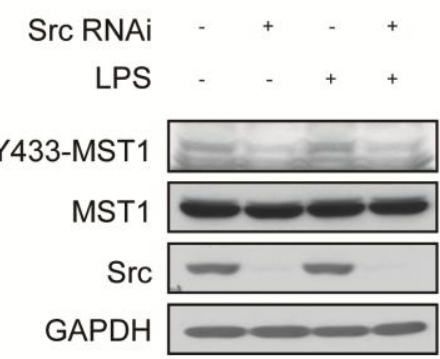

G

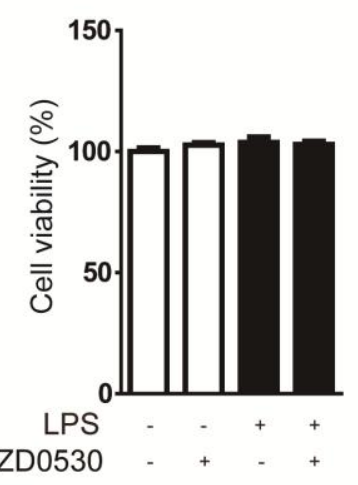

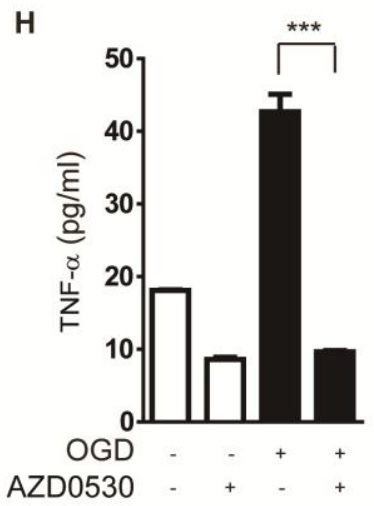

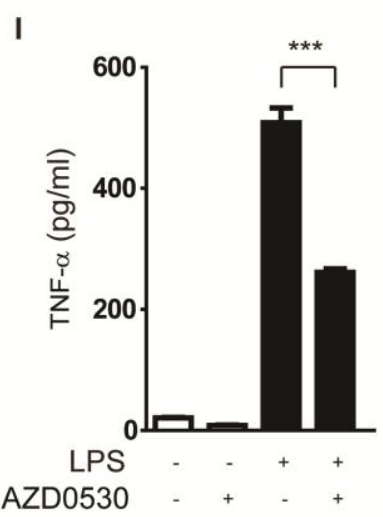

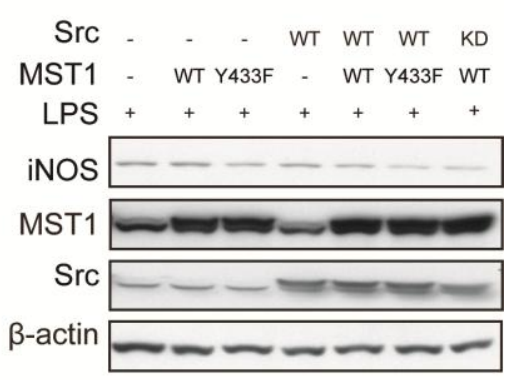


A

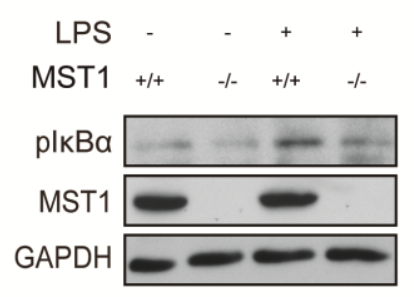

C
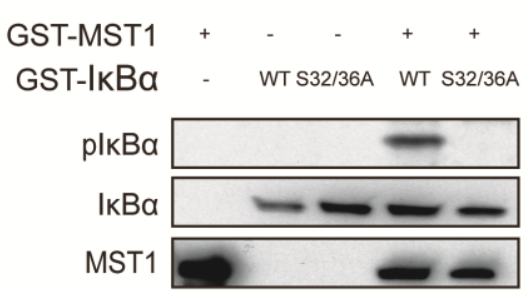

E
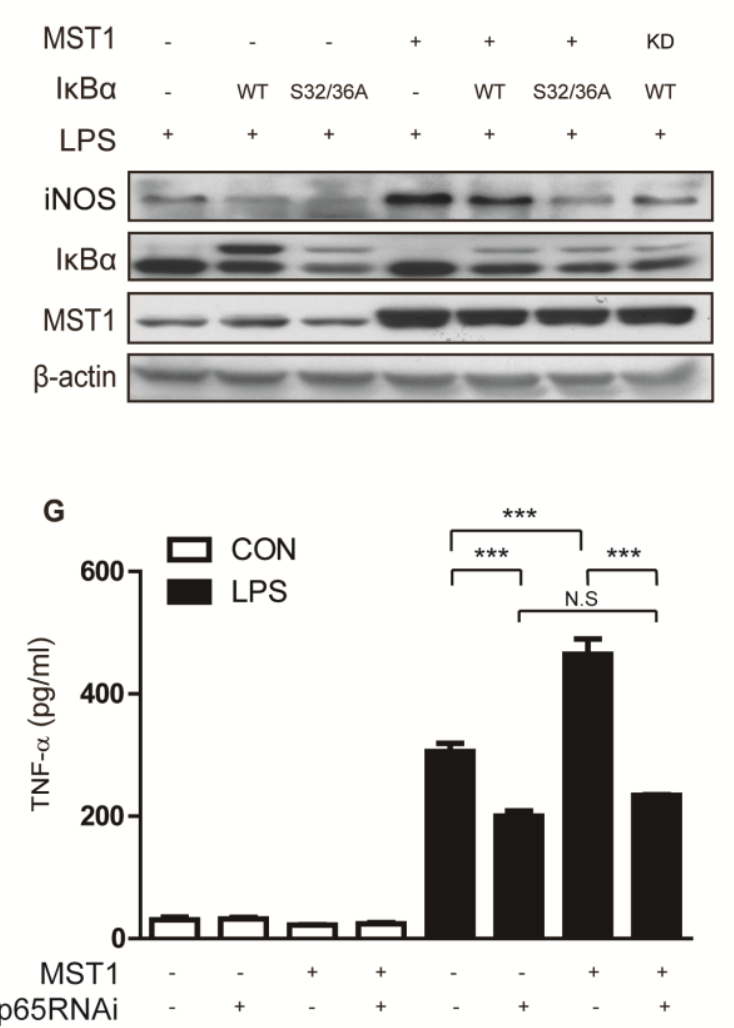

B

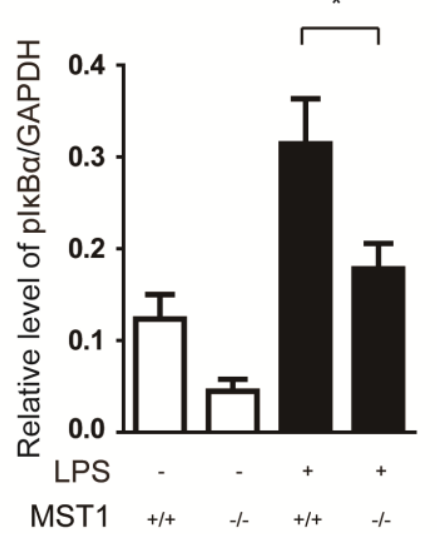

D

GFP-MST1

Flag-IкBa
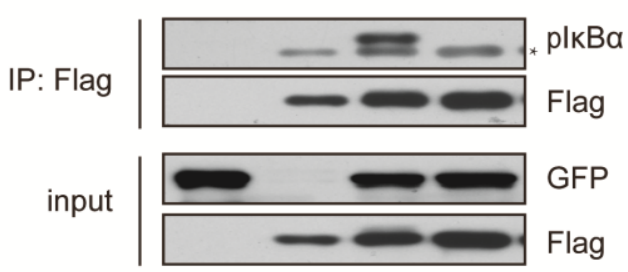

F

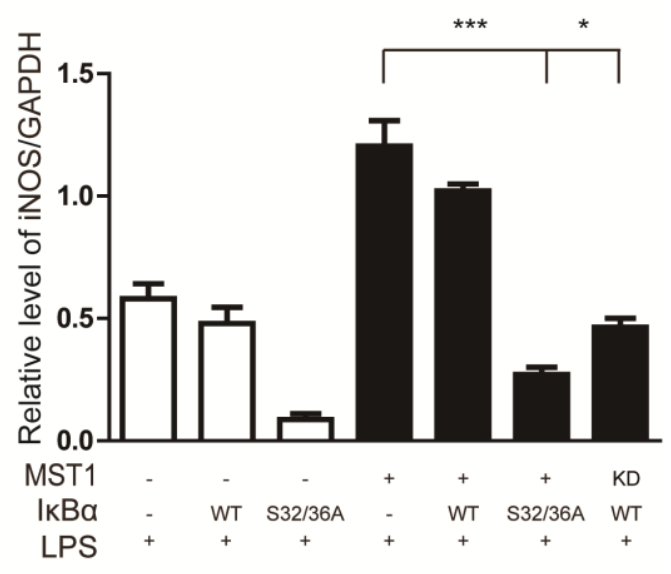

H

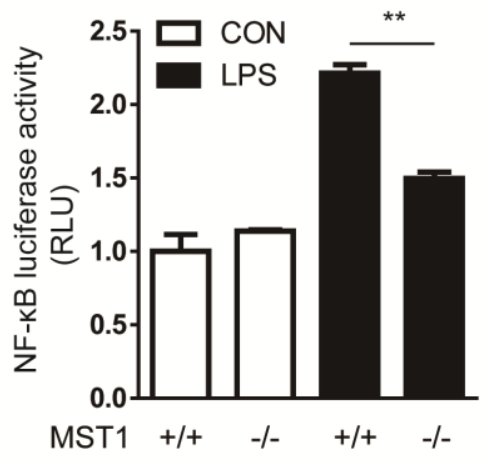


Figure 5

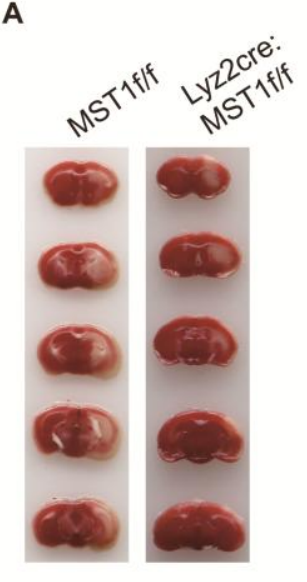

B
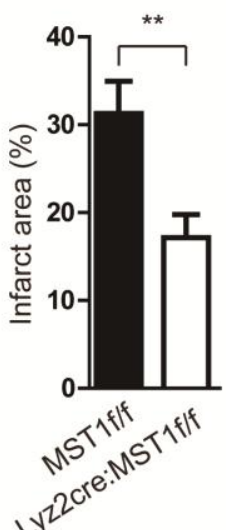

E

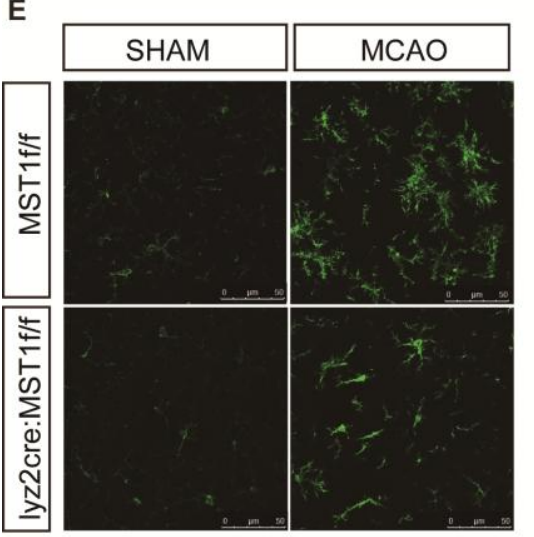

F

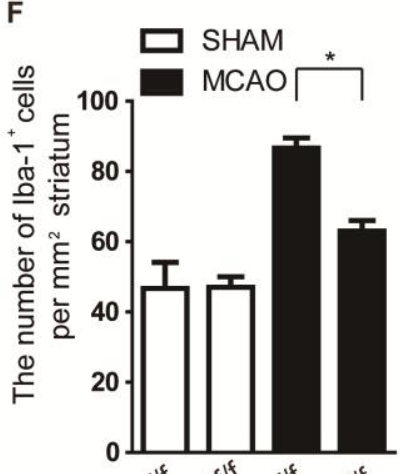

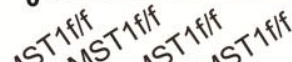

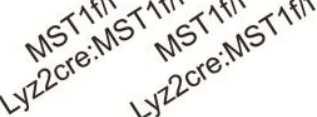

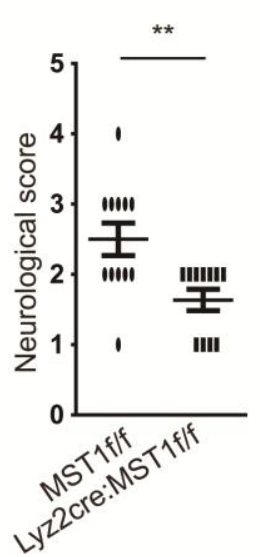

D

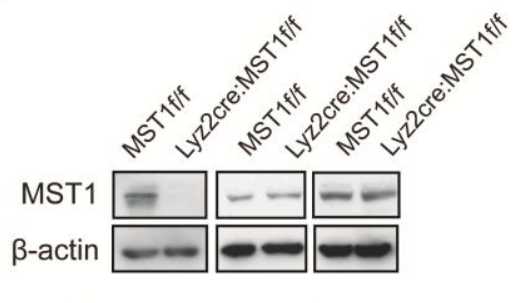

Microglia Neuron Astrocyte

H

G
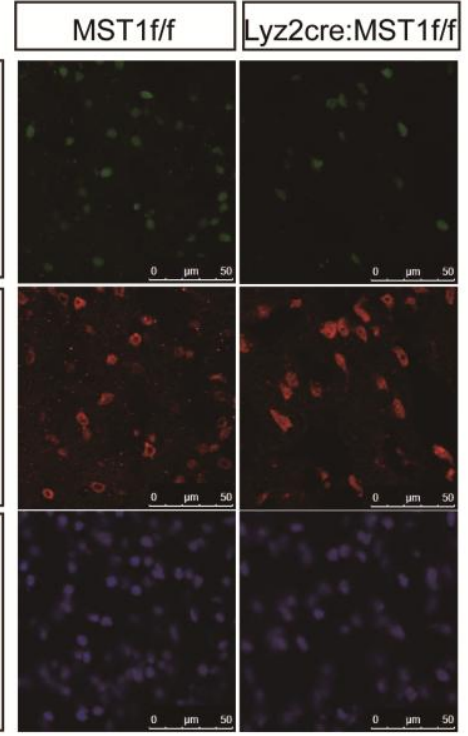

H

MST1f/f

$\square$ Lyz2cre:MST1f/f
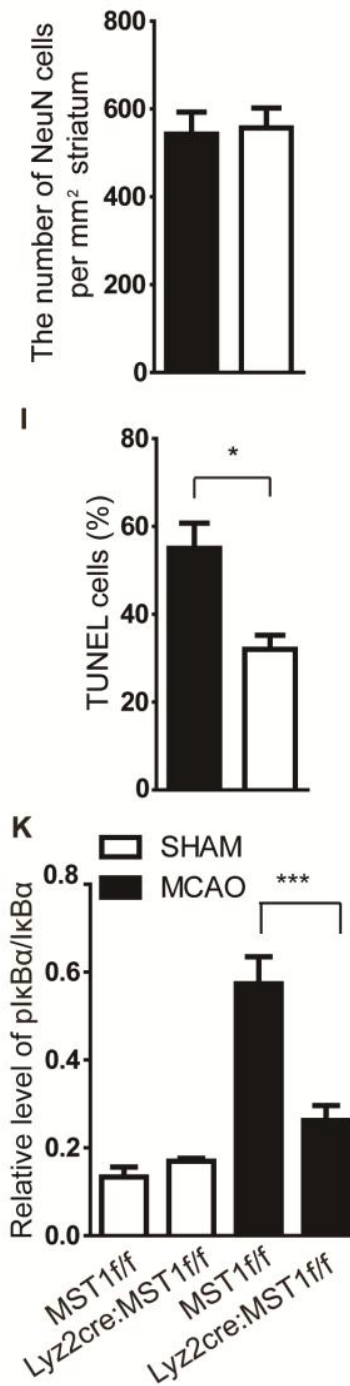
Figure 6

A

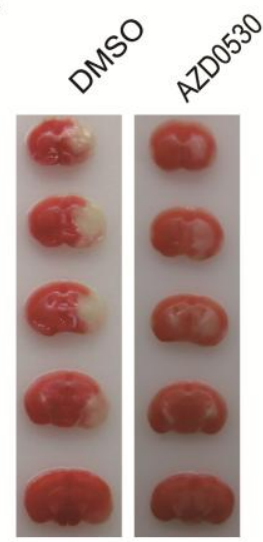

C

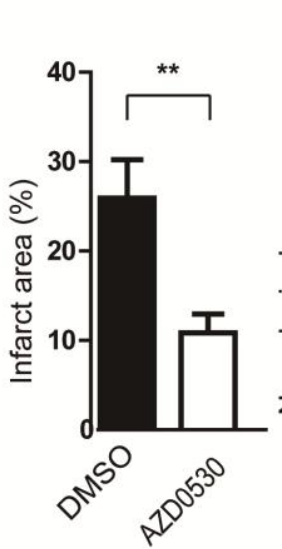

E

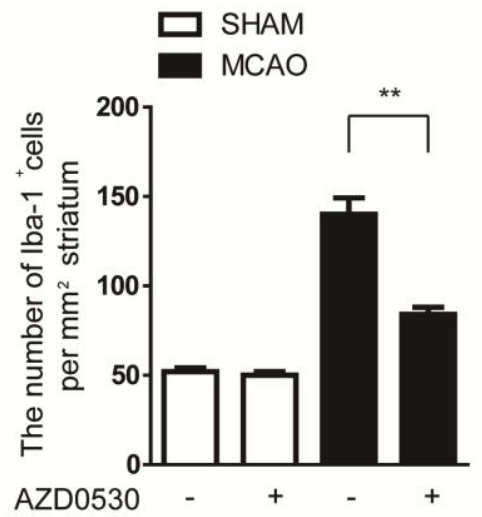

G

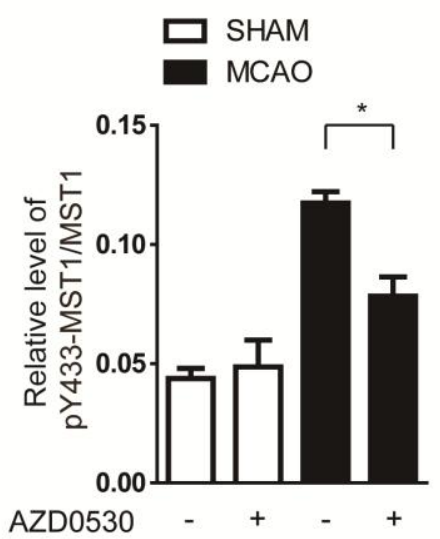

H
D

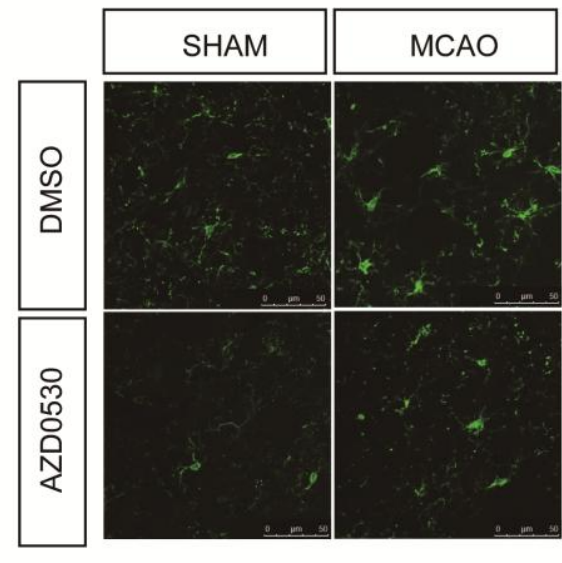

F
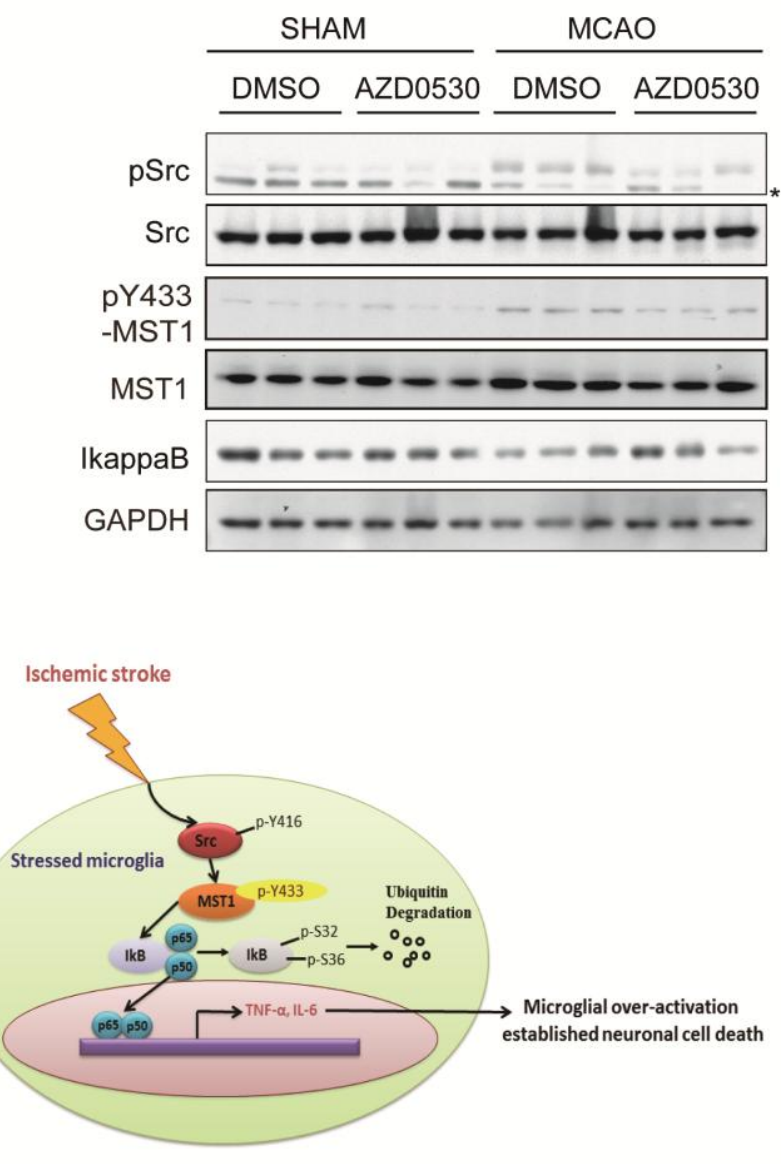